\title{
Mapas conceituais como estratégias no ensino remoto e os desafios dos estudantes nesta modalidade no Curso Técnico em Agropecuária integrado do IFMG - Campus
}

\section{Bambuí}

\author{
Concept maps as strategies in remote learning and the challenges of students in this modality in the \\ Integrated Technical Course in Agriculture at IFMG - Campus Bambuí \\ Mapas conceptuales como estrategias en el aprendizaje remoto y los desafíos de los estudiantes en \\ esta modalidad en el Curso Técnico Agrícola Integrado en IFMG - Campus Bambuí
}

Recebido: 16/06/2021 | Revisado: 24/06/2021 | Aceito: 20/07/2021 | Publicado: 28/07/2021

\author{
Naelana Rodrigues Pereira \\ ORCID: https://orcid.org/0000-0001-6519-6057 \\ Instituto Federal de Educação, Ciência e Tecnologia de Minas Gerais, Brasil \\ E-mail: naelana.p@gmail.com \\ Silvana Lúcia dos Santos Medeiros \\ ORCID: https://orcid.org/0000-0001-7717-4349 \\ Instituto Federal de Educação, Ciência e Tecnologia de Minas Gerais, Brasil \\ E-mail: silvana.medeiros@ifmg.edu.br \\ Joelma Aparecida Nascimento \\ ORCID: https://orcid.org/0000-0001-9859-6313 \\ Instituto Federal de Educação, Ciência e Tecnologia de Minas Gerais, Brasil \\ E-mail: joelmadonascimento@gmail.com
}

\begin{abstract}
Resumo
Este artigo procurou evidenciar as possibilidades para uma prática educativa que elevasse a compreensão do conhecimento. Acredita-se que os mapas conceituais são um artifício metacognitivo que dá sentido ao ensino e a aprendizagem erguendo e edificando saberes. Por este caminho, objetivou-se identificar as propostas acerca da aprendizagem significativa formulada por David Ausubel e a teoria da educação do Joseph Novak, a partir do desenvolvimento da teoria do mapa conceitual como estratégia de ensino-aprendizagem e avaliação dos estudantes no ensino médio integrado em agropecuária do campus Bambuí do IFMG. Assim, o método deste estudo teve por abordagem uma pesquisa qualitativa-quantitativa, considerando o tipo exploratória-descritiva em um estudo de caso, sendo que os dados foram retirados de uma atividade dirigida e questionário aplicado aos estudantes o que propiciou a análise dos dados com o auxílio e utilização do software Microsoft Office Excel® 2021 e do programa estatístico R (R CORE TEAM, 2021). Os resultados obtidos na pesquisa, trilharam a percepção que os mapas conceituais se tornam favoráveis para um ensino que preza um aprendizado significativo, desde que se considerem as nuances permeada pelas condições do alunato. De tal forma, conclui-se que a eficácia na ação pedagógica perpassa distintos processos, e desta forma, deve-se empenhar na reflexão das práticas pedagógicas.
\end{abstract}

Palavras-chave: Mapas conceituais; Ensino não presencial; Aprendizagem significativa.

\begin{abstract}
This article sought to highlight the possibilities for an educational practice that would enhance the understanding of knowledge. It is believed that concept maps are a metacognitive device that gives meaning to teaching and learning, raising, and building knowledge. In this way, the objective was to identify the proposals about meaningful learning formulated by David Ausubel and Joseph Novak's theory of education, from the development of the concept map theory as a teaching-learning strategy and student assessment in integrated secondary education in agriculture at the Bambuí campus of the IFMG. Thus, the method of this study had as an approach a qualitative-quantitative research, considering the exploratory-descriptive type in a case study, and the data were taken from a directed activity and a questionnaire applied to students, which provided the data analysis with the help and use of the Microsoft Office Excel ${ }^{\circledR} 2021$ software and the R statistical program (R CORE TEAM, 2021). The results obtained in the research followed the perception that concept maps are favorable for teaching that values significant learning, if the nuances permeated by the student's conditions are considered. In such a way, it is concluded that the effectiveness in the pedagogical action permeates different processes, and thus, one must engage in the reflection of the pedagogical practices.
\end{abstract}

Keywords: Concept maps; Non-presential teaching; Learning means. 


\begin{abstract}
Resumen
Este artículo buscó resaltar las posibilidades de una práctica educativa que potenciaría la comprensión del conocimiento. Se cree que los mapas conceptuales son un dispositivo metacognitivo que do sentido a la enseñanza y el aprendizaje, elevando y construyendo conocimientos. De esta forma, el objetivo fue identificar las propuestas sobre el aprendizaje significativo formuladas por la teoría de la educación de David Ausubel y Joseph Novak, a partir del desarrollo de la teoría del mapa conceptual como estrategia de enseñanza-aprendizaje y evaluación de los estudiantes en la educación secundaria integrada en agricultura en el Campus Bambuí de la IFMG. Así, el método de este estudio tuvo como abordaje una investigación cualitativo-cuantitativa, considerando el tipo exploratorio-descriptivo en un estudio de caso, y los datos fueron tomados de una actividad dirigida y un cuestionario aplicado a los estudiantes, lo que brindó al análisis de los datos con la ayuda y el uso del software Microsoft Office Excel® 2021 y el programa estadístico R (R CORE TEAM, 2021). Los resultados obtenidos en la investigación respondieron a la percepción de que los mapas conceptuales son favorables para la enseñanza que valora el aprendizaje significativo, siempre que se consideren los matices que permean las condiciones del alumno. De tal forma, se concluye que la efectividad en la acción pedagógica permea diferentes procesos, por lo que se debe involucrar en la reflexión de las prácticas pedagógicas.

Palabras clave: Mapas conceptuales; Enseñanza no presencial; Aprendizaje significativo.
\end{abstract}

\title{
1. Introdução
}

A necessidade de refletir sobre os horizontes no contexto educacional é contínua, bem como a relação teoria e prática. Novas disposições de estudo se aprimoram e sobressaem nas práticas pedagógicas. A estas condições, o ensino, a aprendizagem e a avaliação se engrena em distintas perspectivas que evidenciam proposições didáticas que podem ser implementadas e outras ressignificadas. Frente às mudanças e inovações tecnológicas da atualidade as práticas pedagógicas precisam desenvolver ações significativas. Pensando em tais premissas buscou-se conhecer e aplicar teorias que fomentasse o vínculo dos (das) estudantes com o estudo, no qual sua aprendizagem estivesse em um processo prazeroso, atrativo e eficaz.

Em face da situação pandêmica acarretada pelo vírus da Covid-19, do qual afetou mundialmente as unidades escolares, sobretudo no Brasil, viu-se a necessidade de novas formulações de ensino. Diante disso, o ensino presencial foi substituído pelo ensino remoto (e/ou não presencial) exigindo que mudanças e adaptações fossem consideradas e efetivadas. Logo, a continuidade do ensino só foi possível pela adesão das inovações tecnológicas acompanhado de um olhar diferenciado para o ensino, aprendizagem e avaliação.

De tal modo, o objetivo desta pesquisa centrou seus esforços para identificar as propostas acerca da aprendizagem significativa formulada por David Ausubel e a teoria da educação do Joseph Novak, a partir do desenvolvimento da teoria do mapa conceitual como estratégia de ensino-aprendizagem e avaliação dos estudantes no ensino médio integrado em agropecuária do campus Bambuí no IFMG. Tendo como problemática a delimitação em como o aprendizado pode ser difundido e adquirido pela sistematização do saber utilizando as representações conceituais perpassadas pela disciplina de Zootecnia I em duas turmas que obtiveram modalidade de ensino distintas.

Nessa perspectiva, acreditamos que é de interesse geral o desenvolvimento desta proposta na prática, na medida em que colabora para a promoção de estudantes responsáveis, críticos e criativos que inter-relaciona os pressupostos de uma aprendizagem expressiva como um encontro de possibilidades objetivas. E o uso do mapa conceitual enquanto estratégia fomenta o potencial dos estudantes ao passo que promove a assimilação dos conteúdos. A seguir discorremos sobre estes processos a fim de abordar que tal metodologia traz significativas contribuições para a formação integral das (dos) indivíduos.

\section{Mapas Conceituais no Ensino-Aprendizagem e na Avaliação}

A Educação decorre de processos transversais na formação humana, tornando-se assim, um destaque orientativo para as dimensões e necessidades do ser humano. Portanto, é imprescindível considerar os fatores que influenciam a aquisição de conhecimentos (biológicos, culturais, econômicos, sociais, dentre outros). Hattie (2009) concluiu que o aprender está ligado ao 
aluno e ao professor também, pois, ensino de qualidade e outras premissas devem ter esforços de ambos os lados. Conforme salientado pelo pesquisador:

Não é um método em particular nem um determinado roteiro que fazem a diferença. O que faz a diferença é o empenho em promover uma personalização da aprendizagem, obtendo maior precisão sobre a forma como os alunos estão progredindo nesta aprendizagem e garantir a aprendizagem profissional dos professores sobre como e quando devem fornecer diferentes ou mais eficazes estratégias de ensino e aprendizagem. (Hattie, 2009, p.245).

Para o docente não é fácil trabalhar com turmas heterogêneas; por vezes a causa da reprovação não é somente a dificuldade de aprendizagem, mas sim outros fatores que resultam em baixo rendimento escolar. Não adianta sistematizar a apresentação do roteiro, critérios de avaliação, uma vez que as particularidades aparecem e novas estratégias devem ser pensadas, embora toda a organização da metodologia seja necessária para embasar o referencial conteudista.

A aprendizagem significativa é uma teoria criada por David Ausubel. $\mathrm{O}$ autor afirma que aprender é atribuir significados a novos conhecimentos e, para ele, isso só ocorre a partir da existência de conhecimentos especificamente relevantes, ou seja, o conhecimento prévio. É relevante ratificar que a aprendizagem significativa tem como característica principal a interação dos conhecimentos prévios (conhecimento especificamente relevante) com conhecimentos novos. Um tipo de aprendizagem que Ausubel cita em sua pesquisa é a aprendizagem mecânica. Essa pode ser entendida como um armazenamento de conhecimentos arbitrários, sem conexão com as situações já conhecidas, sem significado, feita sem a participação dos subsunçores, isto é, a aprendizagem mecânica (Xavier, 2019).

A aprendizagem significativa provoca a diferenciação progressiva, onde o novo conceito muda o conceito subsunçores, mas também é modificado por este. Este processo gera a reconciliação interativa, que nada mais é que o relacionamento entre conhecimentos já existentes na estrutura cognitiva do aprendiz, que ocorre a partir da modificação dos subsunçores (Silva, et al., 2017).

A teoria dos Mapas Conceituais foi criada por Joseph Novak em 1972 (Novak e Cañas, 2010) quando trabalhava com muitos dados de entrevistas clínicas piagetianas, e necessitava de um instrumento para organizar esse material. O mapa conceitual surgiu então como uma ferramenta gráfica para representar, organizar, construir e avaliar conhecimentos. A teoria dos mapas conceituais foi desenvolvida tomando por base a teoria da aprendizagem significativa de Ausubel, e possui diversas aplicações para a educação, tais como: a) apresentar um conteúdo; b) estudar um conteúdo; c) fazer síntese de texto; d) organizar o conteúdo programático de uma disciplina; e) avaliar a aprendizagem. O mapa conceitual pode ser construído por metodologia adequada e avaliado por critérios objetivos, e pode ser elaborado a partir do uso de ferramentas digitais.

Nessa perspectiva, a estratégia e recurso do mapa conceitual pode ser um forte aliado enquanto projeto de ensino, aprendizagem e avaliação, pois possibilita identificar os níveis de evolução e investigação do alunato frente ao conteúdo. Para, além disso, essa técnica permite o desenvolvimento da criticidade, haja vista que cada estudante, observará os elementos teóricos, bem como as informações perpassadas pelo conteúdo e será capaz de inferir suas considerações arquitetando uma organização cognitiva sobre $\mathrm{o}$ assunto.

Esta ação educativa de ensino, de aprendizagem e de avaliação pode ser contemplada em detrimento a uma educação integral, já que o método predispõe o envolvimento de potencialidades dando aos estudantes o ensejo de ressignificarem seus aprendizados. O movimento dialógico entre conteúdos e formas pedagógicas cumpre o papel perceptivo de que o ensino não é uma mera reprodução mecânica, portanto a aprendizagem não se pontua pelas verdades e certezas, mas desvela interpretações e informações que fundamentam o saber.

Os mapas conceituais são ferramentas gráficas para organizar e representar o conhecimento. Eles incluem conceitos, geralmente colocados em círculos ou caixas de algum tipo, e relações entre conceitos indicados por uma linha de conexão ligando dois conceitos. Palavras na linha, chamadas de palavras de ligação ou frases de ligação, especificam a relação entre os dois 
conceitos. As proposições são declarações sobre algum objeto ou evento no universo, ocorrendo naturalmente ou construído. As proposições contêm dois ou mais conceitos conectados usando palavras ou frases de ligação para formar uma declaração significativa. Às vezes, elas são chamadas de unidades semânticas ou unidades de significado.

Tolfo afirma que além de promover a aprendizagem significativa em sala de aula, a técnica de elaboração de mapas conceituais ainda pode ser utilizada para alcançar diferentes propósitos que necessitam a compreensão de um determinado assunto. Tolfo (2019, p.05)

Outra característica dos mapas conceituais é que os conceitos são representados de forma hierárquica, ficando os conceitos mais abrangentes e gerais no topo do mapa e os conceitos mais específicos e menos gerais organizados hierarquicamente abaixo. O mapa conceitual pode pertencer a alguma situação ou evento que estamos tentando entender por meio da organização do conhecimento na forma de um mapa conceitual, fornecendo assim o contexto. (Souza, et al., 2016).

Os mapas conceituais têm distintas funcionalidades, não é apenas uma ferramenta de aprendizagem, mas tem também a função de ser utilizada como uma ferramenta de avaliação, o que pode encorajar os (as) estudantes a empregar modelos de aprendizagem de modo significativo (Mintzes et al., 2000; Novak, 1990; Novak; Gowin, 1984). Os mapas conceituais também são eficazes na assimilação de ideias seja elas válidas e inválidas mantidas pelos alunos.

Figura 1 - Uso de mapas conceituais.

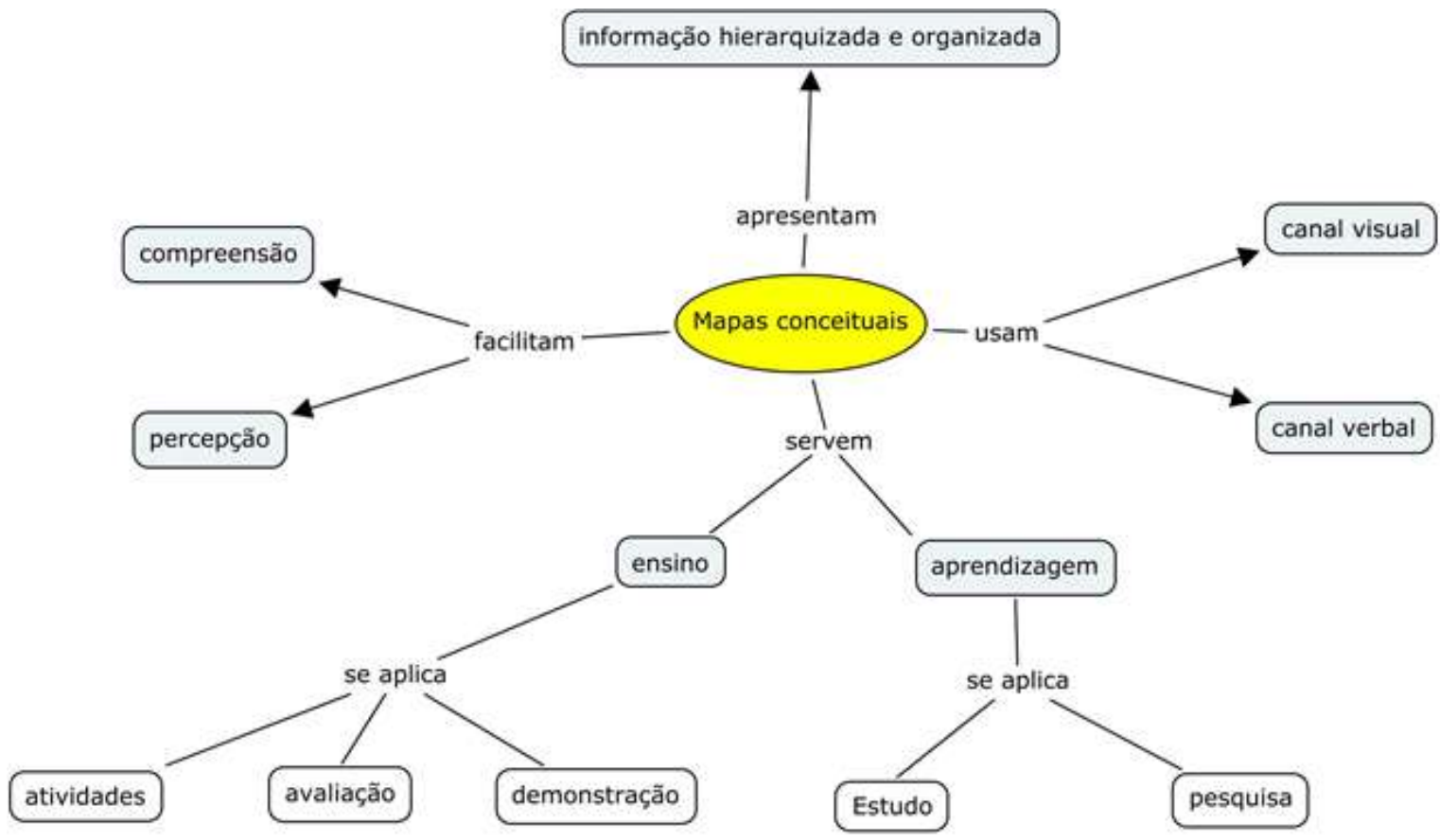

Fonte: De Jorge Horácio "Kotick" Audy. AUDY, J. H. K. Mapas Conceituais e a aprendizagem significativa. https://jorgeaudy.com/2014/06/08/mapas-conceituais/.

Neste sentido, Correia e Nardi (2019), prenunciam uma abordagem a partir dos mapas conceituais que decorrem de um processo preparatório, do qual o planejamento das atividades cumpra alguns requisitos básicos e o procedimento avaliativo para a compreensão dos (das) estudantes. Vejamos: 
Figura 2 - Preparação para o uso do mapa conceitual em um modelo avaliativo.

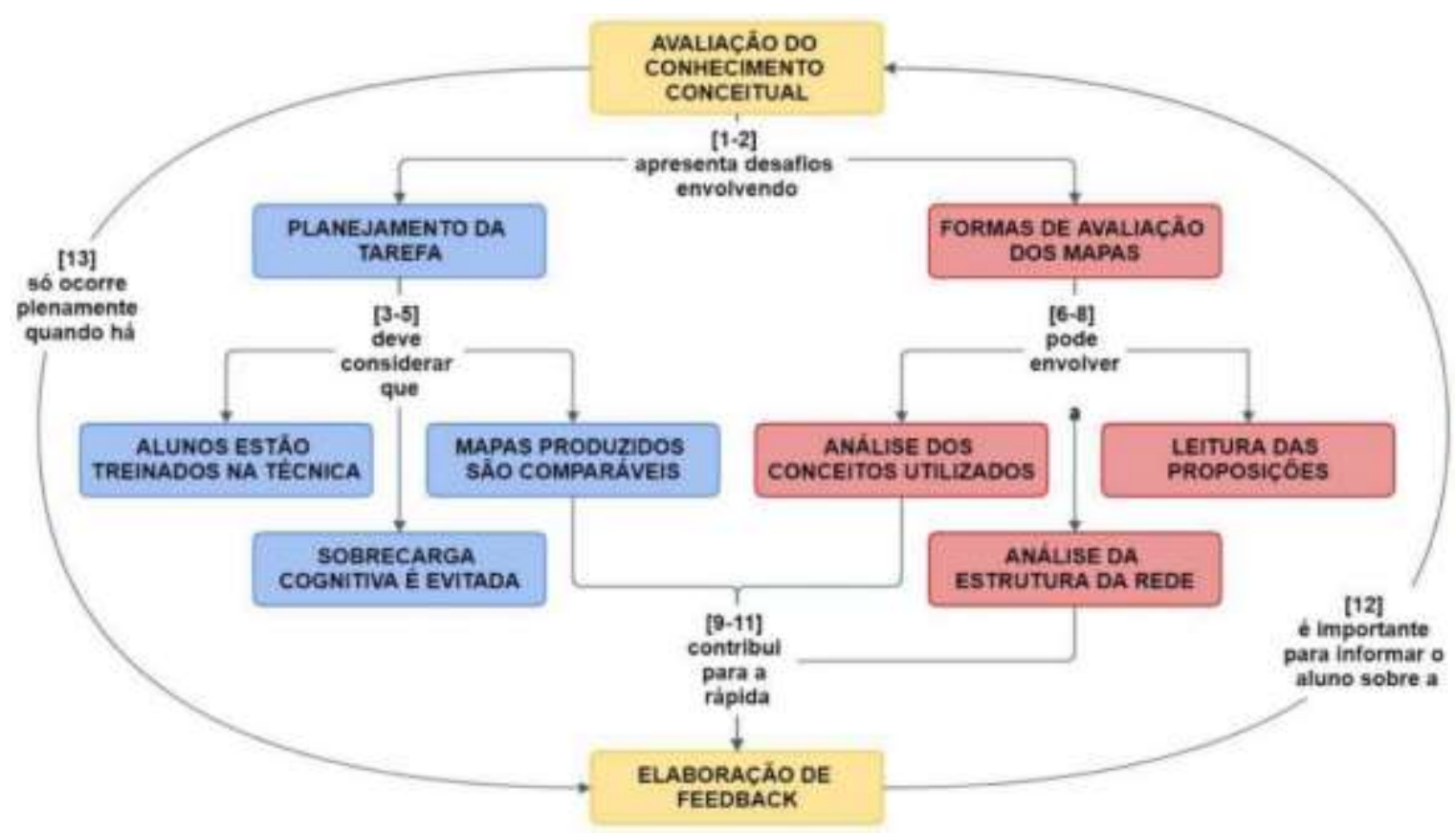

Fonte: De "O que revelam os mapas conceituais dos meus alunos? Avaliando o conhecimento declarativo sobre a evolução do universo" de P. R. M. Correia e A. Nardi, 2019, p.686. DOI: https://doi.org/10.1590/1516-731320190030008

Evidentemente, este processo preparatório requer uma reflexão comprometida com o aprimoramento do ensino, da aprendizagem e da avaliação. Exige ainda uma compreensão avaliativa que não encara o conteúdo como uma mera transmissão linear e/ou mecânica, mas propõe sentido, designa desafios, expõe dificuldades que pode resultar em aprendizagens significativas para os sujeitos.

A partir dos mapas conceituais torna-se possível a tomada de decisão, de consciência neste percurso do aprender, e, não apenas para que o (a) professor determine suas alternativas de ensino, mas também para que os (as) estudantes constituam como atores principal de seu aprendizado.

\section{Metodologia}

O Instituto Federal de Educação de Ciência e Tecnologia de Minas Gerais - Campus Bambuí oferta o Curso Técnico em Agropecuária Integrado ao Ensino Médio na modalidade presencial. A organização curricular do curso proposto está estruturada em disciplinas do núcleo comum e disciplinas técnicas anuais. Nessa perspectiva, o modelo de ensino-aprendizagem e avaliação pressupõe a interação professor/aluno. A carga total do curso é de 3941,14 horas. O prazo para integralização do curso é de no mínimo três anos e máximo de seis anos. As aulas são realizadas em unidades de cinquenta minutos, divididas de acordo com a Matriz Curricular. A disciplina Zootecnia I situada na série/modulo -1, aborda os conteúdos de avicultura de corte e postura e piscicultura, sendo a carga horária de 133,33 horas-aula.

Devido a Resolução No 8 de 03 de julho de 2020 da qual dispõe de mediáveis diretrizes para as atividades do Ensino, Extensão, Pesquisa e Inovação no âmbito do IFMG - Campus Bambuí, durante o período de Estudos Não Presenciais (ENP) em função da excepcionalidade causada pela pandemia do novo Coronavírus (Covid-19), a presente pesquisa buscou construir um conhecimento sistemático a partir de dois casos singulares. Sendo um deles realizado em seu contexto natural, e outro testado nas novas configurações determinadas, mas ambas considerando a percepção e compreensão dos atores sociais. 
Assim, o método deste estudo teve por abordagem uma pesquisa qualitativa-quantitativa, considerando o tipo exploratória-descritiva em um estudo de caso voltada precisamente para a área agropecuária o que propiciou a exposição da estratégia de ensino a partir do mapa conceitual.

Os alunos envolvidos neste estudo cursavam a disciplina curricular, Zootecnia I (Avicultura de Corte e Postura) no semestre em que foram gerados os dados para esta pesquisa. Caminhando nessa direção, os dados da pesquisa foram gerados a partir da disciplina, com carga horária de 66.66 horas aula. Essa disciplina, tem duração de um semestre, sendo ofertada aos alunos das turmas do Curso como ENP, contudo uma turma teve a disciplina correspondendo o primeiro semestre e a outra turma o segundo semestre do ano letivo de 2020.

As aulas aconteciam uma vez por semana no período noturno, das 19h00min às 20h15min em consenso com a turma. As atividades propostas eram enviadas com o prazo de quinze dias e postadas no Ambiente Virtual de Aprendizagem (AVA) do IFMG Campus Bambuí disponibilizado através do sistema Moodle. Ressalta-se que em razão da pandemia e da modalidade de ENP foi elevado o número de estudantes faltosos, haja visto que na Turma 1 o número de matriculados correspondia a 28 alunos, no entanto, participando das aulas foram apenas um grupo de dezesseis estudantes. E na Turma 2 havia 29 alunos matriculados, do qual somente doze estudantes estiveram presentes. Além disso, cerca de 50\% dos alunos de cada turma acompanhavam as aulas por videoconferência. Os demais alunos baseavam-se somente no material bibliográfico disponibilizado, dentre outros.

Os conteúdos foram divididos em dois tópicos: 1) Avicultura de Corte e 2) Avicultura de Postura. Cada tópico contava primeiramente com a realização de uma atividade: estudo dirigido e para finalização dos estudos a elaboração de um mapa conceitual sobre um tema correspondente ao tópico. As aulas eram ministradas por videoconferência sendo disponibilizadas as gravações das mesmas e material bibliográfico para consulta.

O estudo dirigido teve por intuito direcionar o conteúdo de forma sequenciada e didática. Utilizando as diretrizes da Teoria de Ausubel, aprendizagem significativa na construção do conhecimento. Mediou-se então, a interação de conhecimentos prévios através de aspectos identificáveis na biologia, física, química, matemática, geografia, história dentro do contexto da avicultura, para que deste modo os alunos e as alunas assimilassem novos conceitos ligados ao conteúdo. O estudo do conteúdo fez com que os (as) estudantes buscassem os conhecimentos prévios, conhecidos como subsunçores (ideias âncoras) e a interação com os novos conceitos, construindo uma ampliação da aprendizagem. Vale ressaltar que a aprendizagem significativa requer um material apreciável, predisposição para aprender e a organização prévia do saber. Portanto, para construir estes processos foram utilizadas videoaulas, cujo material foi elaborado no programa PowerPoint com fotos, figuras, tabelas, referências bibliográficas, dentre outros meios de ensino, buscando ilustrar e apresentar o conteúdo, contextualizando assim, o tema com aspectos socioeconômicos, culturais, políticos, tecnológicos, a fim de familiarizar os (as) estudantes com o assunto, a partir das suas vivências.

Para a finalização do conteúdo como estratégia de ensino, aprendizagem e avaliação foi feito atividades individualmente, do qual se solicitava a elaboração do mapa conceitual. Na construção do mapa foi explicado pela professora quais eram os objetivos da atividade, utilizou-se um exemplo como modelo da criação de um mapa conceitual. Teve um roteiro sobre a síntese do tópico estudado, evidenciando ideias centrais e a elaboração de uma lista que identificasse os conceitos-chave que precisavam ser incluídos do mais geral ao mais específico. Em síntese a proposta foi a ideia central: Manejo de frangos de corte que foi exposto em fases: Preparo do galpão, recepção dos pintainhos, fase pré-inicial, fase inicial, fase de crescimento, fase final e abate das aves, com as práticas de manejo específicas em cada fase como: instalações, equipamentos, arraçoamento, programa de luz, limpeza e desinfecção dos equipamentos e ambiente, manejo da cama, ambiência do galpão, controle zootécnico, dentre outras.

Já para a avaliação do mapa conceitual foi adotada uma escala entre 0 e 10. E para o desempenho dos alunos, utilizouse os critérios de: 
- Hierarquia e organização dos conceitos: Observou-se neste critério a relação e a interdependência dos conceitos sobre o tema;

- Compreensão do tema: Observou-se neste critério se os conceitos foram evidenciados de forma clara com as interações que explicavam as situações das ideias e;

- Estudo e pesquisa: Observou-se neste critério se os conceitos foram estabelecidos pelo estudo, compreensão e pesquisa sobre o tema. Verificando se houve a síntese completa do tema.

Dentro das atividades havia também um questionário que teve como objetivo obter informações sobre o perfil acadêmico dos participantes e informações acerca da realidade enfrentada na modalidade de ENP ao longo do semestre.

Foram avaliadas duas turmas do Curso Técnico em Agropecuária. As turmas foram divididas em:

Turma 1: Alunos que tiveram o conteúdo de avicultura de corte com parte do ensino presencial e outra parte não presencial, o conteúdo de avicultura de postura não presencial e ainda aulas práticas no laboratório de avicultura quando presencial. Essa turma correspondeu ao primeiro semestre do ano letivo de 2020;

Turma 2: Alunos que tiveram o conteúdo de avicultura de corte e postura não presencial e não tiveram aulas práticas no laboratório de avicultura. Essa turma correspondeu ao segundo semestre do ano letivo de 2020.

Com o retorno da atividade e questionário foi possível analisar os dados com o auxílio de planilhas eletrônicas, usando o software Microsoft Office Excel® 2021. Os dados provenientes dos questionários foram tabulados e transformados em valores nominais e em percentuais, e, a partir deles, foram construídos gráficos com o objetivo de facilitar a interpretação de todos os resultados obtidos. No presente estudo, valendo-se, das notas dos alunos obtidas nas atividades, utilizou-se a análise de cluster hierárquica realizando a função hcut do pacote factoextra do programa estatístico R (R CORE TEAM, 2021). Para analisar as respostas dos alunos nos questionários utilizou-se histogramas que foram construídos pelos pacotes ggplot2 e barplot do programa estatístico R.

\section{Resultados e Discussão}

Esta seção se divide em três pontos de apresentação, os dois primeiros são colocados a fim de elucidar e mostrar os dados da pesquisa - resultados, o último ponto por sua vez, sintetiza a discussão dos resultados. Desta forma, o primeiro tópico diz respeito aos Mapas Conceituais das duas turmas, o segundo, uma análise do questionário aplicada a cada turma e por fim se pontua uma discussão dos resultados obtido.

\subsection{Mapas conceituais}

Como parte da tríade ensino-aprendizagem-avaliação foi planejado para ambas as turmas $\left(\begin{array}{lll}1 & \text { e } & 2\end{array}\right)$ um estudo individualizado sobre Avicultura de Corte e Avicultura de Postura. Logo depois, se propôs um estudo dirigido sobre cada assunto e enquanto atividade de estudos não presenciais a produção de um mapa conceitual que consistia na temática das aulas.

Deste modo, procurou-se esclarecer por meio de figuras e aportes teóricos a estrutura e formato de um mapa conceitual, e, como esta ferramenta pode ser um instrumento de representação, organização e visualização de conceitos e assuntos.

Após, tais evidências apresentadas, propôs-se que os (as) estudantes expusessem seus conhecimentos utilizando o instrumento mapa conceitual sob um contexto específico: "manejo de frangos de corte". Com isso, obtivemos alguns resultados que estão descritos a seguir por turma. 


\subsubsection{Avaliação do mapa conceitual - Turma 1}

As notas de avaliação dos dezesseis alunos da Turma 1 de Avicultura no manejo de frangos de corte na qual utilizou-se o mapa conceitual (informação hierarquizada e organizada, compreensão do tema, estudo e pesquisa) estão agrupadas na Figura 3.

Figura 3 - Análise de cluster hierárquica com as notas dos alunos da Turma 1 na atividade utilizando mapa conceitual.

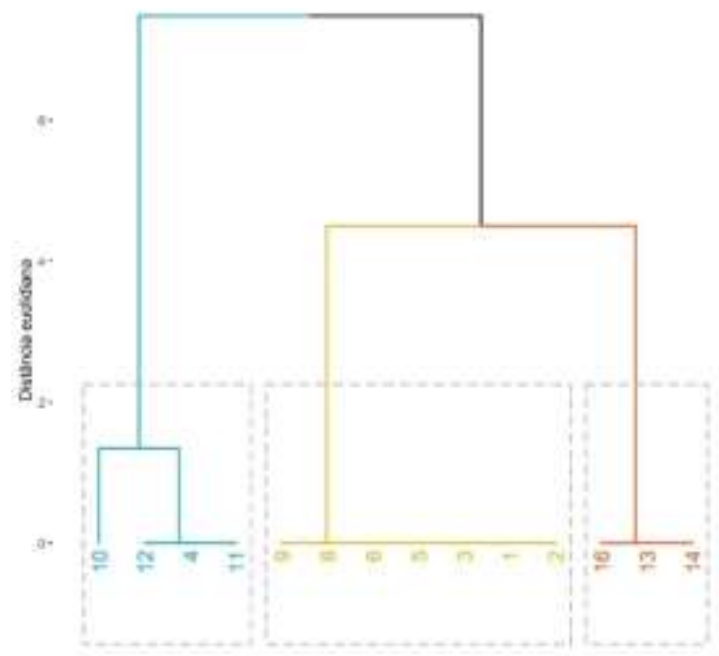

Fonte: Autores (2021).

A análise de cluster é uma técnica estatística usada para classificar elementos em grupos, de forma que as informações dentro de um mesmo cluster sejam muito parecidos, e os elementos em diferentes clusters sejam distintos entre si.

De acordo com os grupos criados na análise de cluster (Figura 3), o grupo dos alunos (10, 12, 4 e 11) não fizeram o mapa conceitual, não entenderam ou apenas copiaram o mapa conceitual de outros alunos. Esse grupo apresentou notas que variaram de cinco a seis pontos. O segundo grupo são dos alunos $(9,8,6,5,3,1$ e 2) que obtiveram nota com média oito pontos. Eles fizeram o mapa, contudo faltaram algumas informações no mapa conceitual e apresentaram alguma dificuldade para ligar os conceitos. O terceiro grupo de alunos $(16,13$ e 14) são os alunos que entenderam o tópico pelos estudos e representaram o aprendizado na realização do mapa conceitual. Dois alunos não fizeram o mapa conceitual (alunos 7 e 15).

Na Tabela 1 têm-se a análise descritiva das notas de avaliação dos alunos da Turma 1 na informação hierarquizada e organizada, compreensão do tema, estudo e pesquisa, e avaliação. Esses critérios foram utilizados para avaliação do mapa conceitual dos alunos.

Tabela 1 - Análise descritiva das notas de avaliação dos alunos da Turma 1.

\begin{tabular}{cccc}
\hline $\begin{array}{c}\text { Variáveis } \\
\text { descritivas }\end{array}$ & $\begin{array}{c}\text { Informação } \\
\text { hierarquizada e } \\
\text { organizada }\end{array}$ & $\begin{array}{c}\text { Compreensão do } \\
\text { Tema }\end{array}$ & $\begin{array}{c}\text { Estudo e } \\
\text { pesquisa }\end{array}$ \\
\hline Média & 6,8 & 6,8 & 6,8 \\
Mínimo & 0,0 & 0,0 & 0,0 \\
Máximo & 10,0 & 10,0 & 10,0 \\
Mediana & 8,0 & 8,0 & 8,0 \\
Amplitude & 10,0 & 10,0 & 10,0 \\
\hline
\end{tabular}

Fonte: Autores (2021). 
A Turma 1 obteve notas que na média ficaram entre 6,8 pontos (quatorze alunos com nota e dois alunos não fizeram o mapa conceitual), e com nota mediana de 8 pontos nas atividades. Alguns alunos não fizeram o mapa conceitual ou não entregaram, por isso a nota mínima foi zero (alunos 7 e 15).

\subsubsection{Avaliação do mapa conceitual - Turma 2}

As notas de avaliação dos doze alunos da Turma 2 de Avicultura no manejo de frangos de corte na qual utilizou-se os mapas conceituais sob a mesma padronização do proposto para Turma 1 estão agrupadas na Figura 4.

Figura 4 - Análise de cluster hierárquica com as notas dos alunos da Turma 2 na atividade utilizando mapa conceitual.

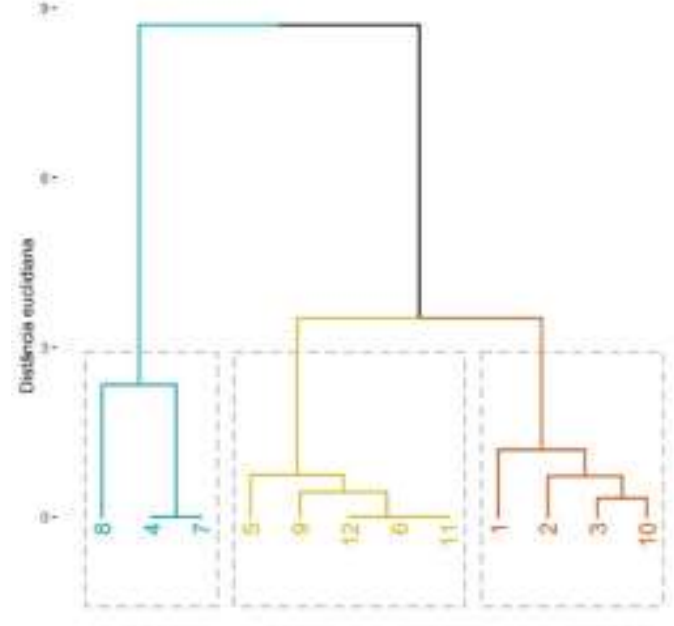

Fonte: Autores (2021).

De acordo com os grupos criados na análise de cluster (Figura 4), o grupo dos alunos $(8,4$ e 7 ) no mapa indica que os alunos não fizeram o mapa, não entenderam ou apenas copiaram o mapa conceitual. Esse grupo apresentou notas variando entre 0 e 3 . O segundo grupo são dos alunos $(5,9,12,6$ e 11) que obtiveram nota entre seis e sete. Eles fizeram o mapa, mas faltaram algumas informações e apresentaram dificuldades na ligação dos conceitos no mapa conceitual. O terceiro grupo de alunos (1, 2, 3 e 10) são os alunos que conseguiram demonstrar entendimento do tópico e o aprendizado na realização do mapa conceitual.

Na Tabela 2 têm-se a análise descritiva das notas de avaliação dos alunos da Turma 2 na informação hierarquizada e organizada, compreensão do tema, estudo, pesquisa e avaliação.

Tabela 2 - Análise descritiva das notas de avaliação dos alunos da Turma 2.

\begin{tabular}{ccccc}
\hline $\begin{array}{c}\text { Variáveis } \\
\text { descritivas }\end{array}$ & $\begin{array}{c}\text { Informação } \\
\text { hierarquizada e } \\
\text { organizada }\end{array}$ & $\begin{array}{c}\text { Compreensão } \\
\text { do Tema }\end{array}$ & $\begin{array}{c}\text { Estudo } \\
\text { Pesquisa }\end{array}$ & Atividade \\
\hline Média & 6,3 & 6,3 & 6,4 & 6,7 \\
Mínimo & 0,0 & 0,0 & 0,0 & 0,0 \\
Máximo & 10,0 & 10,0 & 10,0 & 10,0 \\
Mediana & 7,0 & 7,0 & 7,0 & 6,5 \\
Amplitude & 10,0 & 10,0 & 10,0 & 10,0 \\
\hline
\end{tabular}

Fonte: Autores (2021). 
A Turma 2 teve notas que na média ficou entre 6,3; 6,4 e 6,7, com uma mediana de 7 e 6,5 na atividade. Alguns alunos não fizeram o mapa conceitual ou não entregaram, por isso o mínimo nas notas foi nota zero.

\subsection{Questionário aos estudantes}

Devido ao retorno com a atividade do mapa conceitual dedicamos os esforços em incluir um questionário para compreender melhor o perfil dos (das) estudantes, suas observações e obter uma avalição por parte deles em relação a disciplina e as propostas elencadas.

O questionário contou com dez questões, das quais havia perguntas objetivas de múltiplas escolhas, além de questões discursivas. Diante disso, obteve-se alguns resultados que estão descritos, por turmas, abaixo.

\subsubsection{Levantamento do perfil acadêmico - Turma 1}

Para avaliar o perfil acadêmico usou-se como base o questionário sopesando os indicadores socioeconômicos dos (das) estudantes como: local de moradia (área urbana ou rural - Figura 5 - A), equipamentos utilizados para acessar a internet no estudo não presencial (Figura 5 - B), funcionamento da internet nesses locais (Figura 5 -C) e dificuldades enfrentadas na modalidade de ensino não presencial (Figura 5 - D).

Figura 5 - Perfil acadêmico de 16 alunos da Turma 1 no ensino não presencial.

A

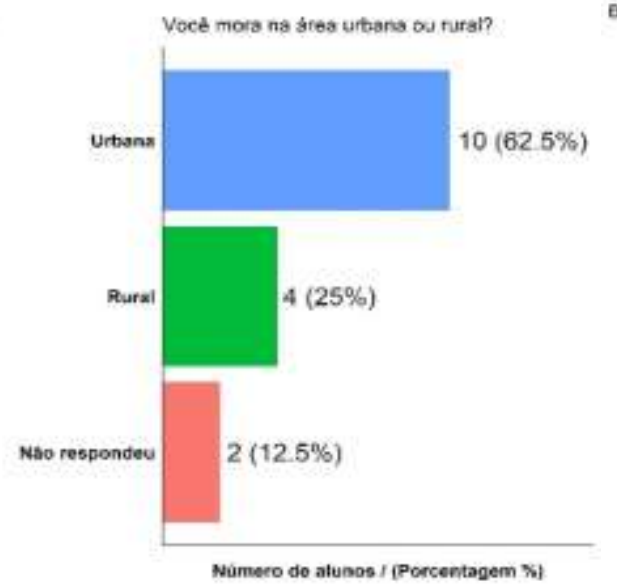

c

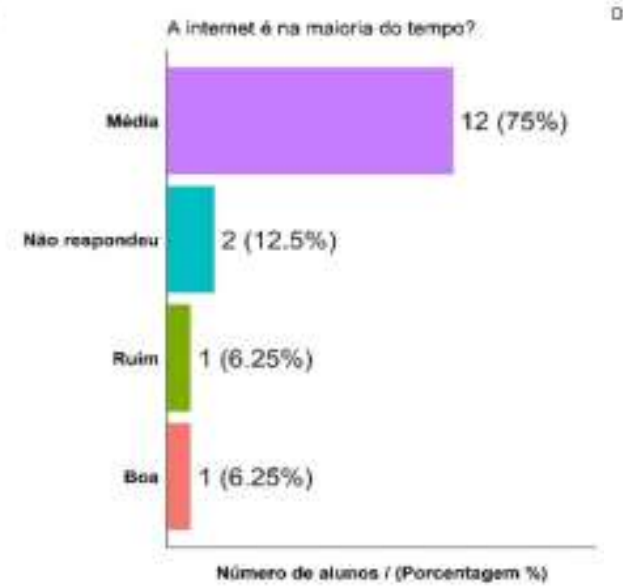

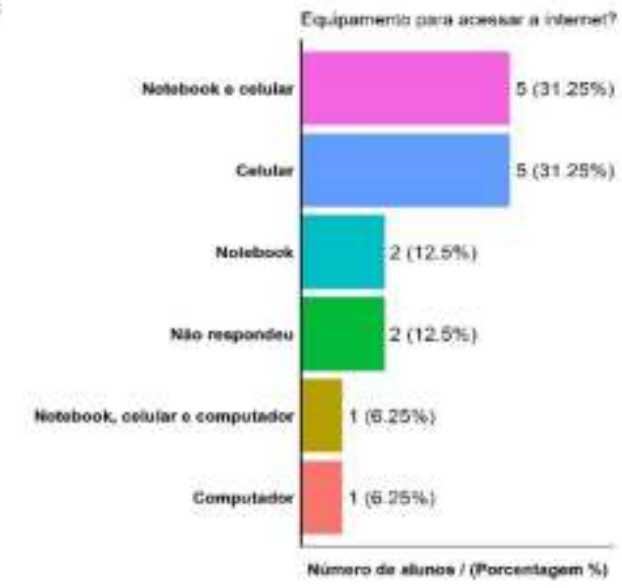

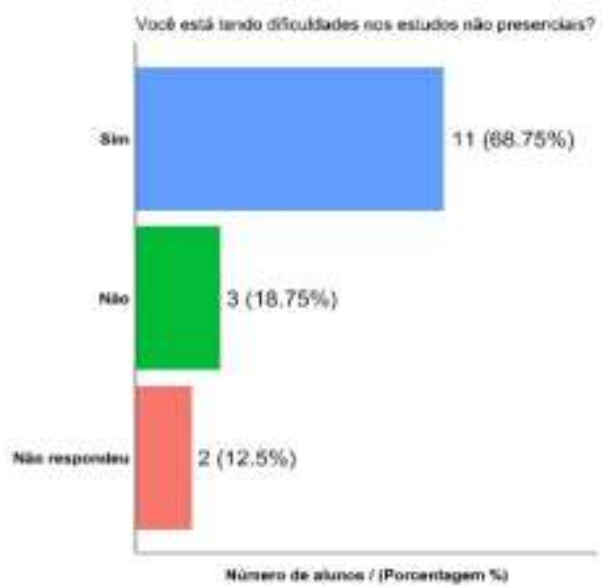

Fonte: Autores (2021). 
Os dezesseis alunos da disciplina de Avicultura são de municípios do Centro-Oeste Mineiro, sendo que 62,5\% deles são da área urbana, 25\% da área rural e 12,5\% optaram por não responder (Figura 4 - A). As cidades mineiras citadas como moradia atual dos alunos foram: Bambuí, Candeias, Carmopólis de Minas, Córrego Dantas, Ibiá, Luz, Medeiros, Pratinha, São Gotardo e Serra da Saudade.

Quanto aos equipamentos utilizados observou-se que para acessar a internet na realização das atividades na modalidade do ENP cinco alunos (31,5\%) usavam notebook e celular, outros cinco alunos (31,25\%) tinham somente o celular para os estudos, dois alunos $(12,5 \%)$ usavam o notebook, porcentagem equivalente também a outros dois alunos que não responderam a pergunta representando (12,5\%), um aluno $(6,25 \%)$ possuía notebook, celular e computador e outro $(6,25 \%)$ sendo um aluno, tinha apenas o computador.

Para identificar a qualidade de acesso à internet foi verificado que doze alunos (75\%) qualificaram a internet de qualidade média, dois alunos (12,5\%) não responderam e apenas um aluno $(6,25 \%)$ classificou a internet como ruim, enquanto outro aluno $(6,25 \%)$ tinha acesso a uma internet de boa qualidade.

Para dar continuidade à investigação do perfil acadêmico dos alunos questionamos a respeito das dificuldades em relação ao ensino na modalidade de ENP. Sendo assim, onze alunos $(68,75 \%)$ responderam que estavam tendo dificuldades, três alunos $(18,75 \%)$ responderam que não tinham dificuldades e dois alunos (12,5\%) não responderam.

\subsubsection{Levantamento do perfil acadêmico - Turma 2}

Seguindo o padrão da Turma 1, utilizou-se o questionário para avaliar o perfil acadêmico dos alunos e alunas da turma 2, como onde eles moravam (área urbana ou rural - Figura 6 - A), quais os equipamentos que utilizavam para acessar a internet no estudo não presencial (Figura 6 - B), como era a internet nesses locais (Figura 6 -C) e se os alunos tinham dificuldades no ensino não presencial (Figura 6 - D). 
Figura 6 - Perfil acadêmico de 12 alunos da Turma 2 no ensino não presencial.
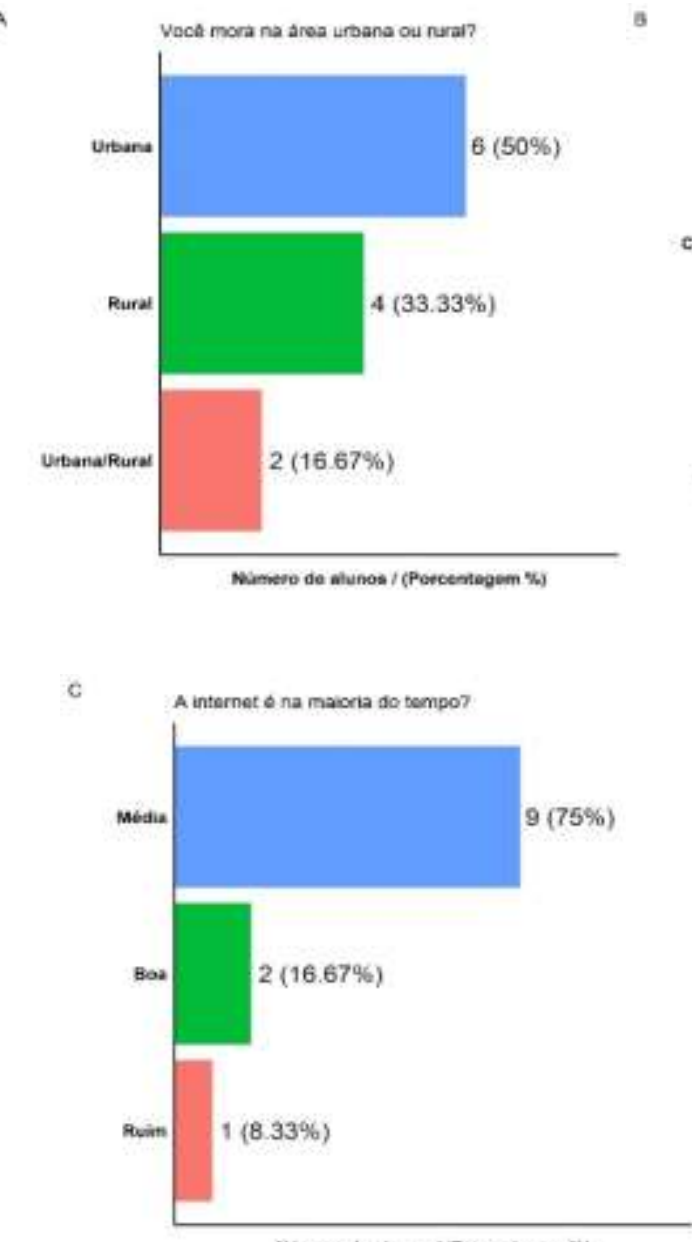

Nümere de alunes $i$ (Pareentagam $*$ )
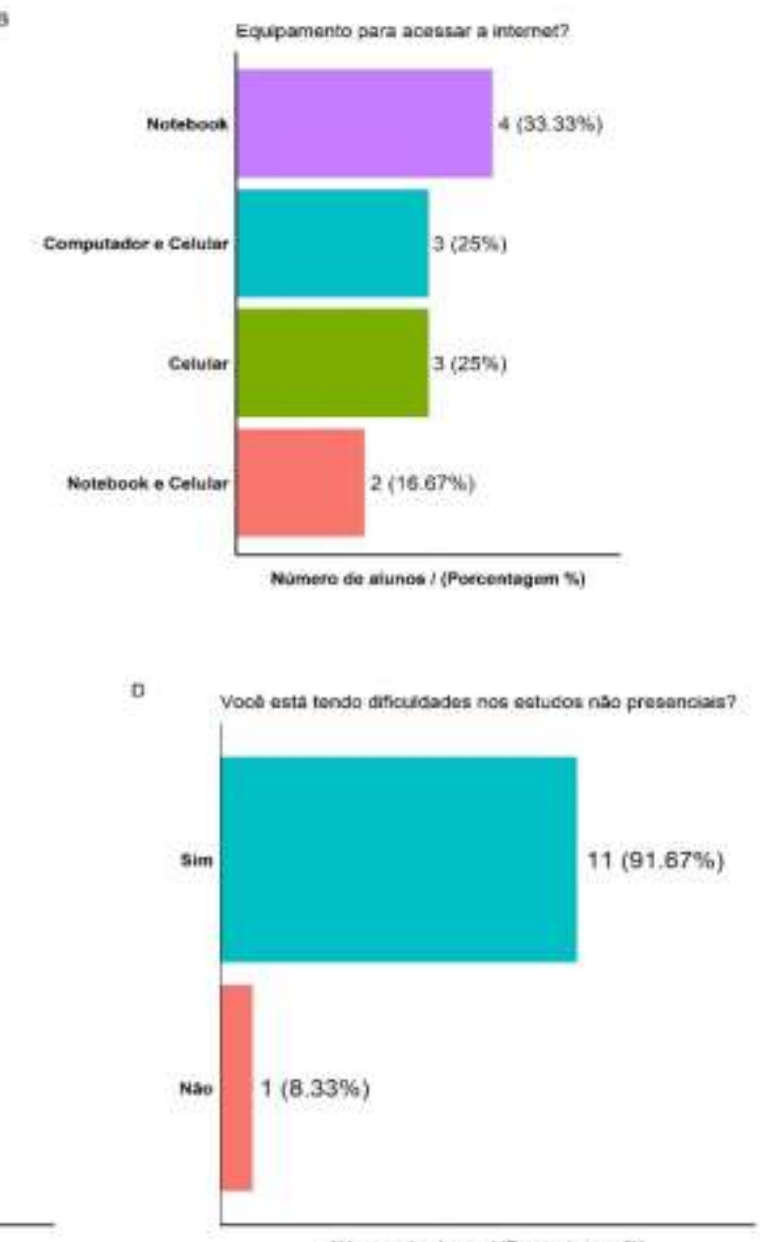

Nümero do alunos / (Porcentagem $\mathrm{k}$ )

Fonte: Autores (2021).

Os doze estudantes da disciplina de Avicultura da Turma 2 são de Minas Gerais, sendo que 50\% equivalente a seis alunos são da área urbana, 33,33\% quatro estudantes da área rural e 16,67\% correspondente a dois educandos, se classificaram enquanto urbana/rural (Figura 6 - A). As cidades citadas foram Bambuí, Campos Altos, Codisburgo, Córrego Dantas, Cristais, Felixlândia, Iguatama, Medeiros e São Roque de Minas.

Observou-se quanto aos equipamentos utilizados que para acessar a internet na realização das atividades na modalidade de Ensino Não Presencial (ENP), quatro alunos (33,33\%) usavam computador, três alunos (25\%) tinham Computador e o celular para os estudos, três alunos (25\%) usavam somente o celular, dois alunos (16,67\%) possuíam notebook e celular (Figura 6 - B).

No que diz respeito a qualidade de acesso à internet foi verificado que nove alunos (75\%) qualificaram a internet como de qualidade média, dois alunos (16,7\%) classificaram a internet como boa e um aluno $(6,25 \%)$ tinha acesso ruim (Figura 6 C).

Quanto às dificuldades em relação ao ensino na modalidade de ENP, onze alunos $(91,67 \%)$ responderam enfrentarem dificuldades e somente um aluno $(8,33 \%)$ respondeu que não tinha dificuldades (Figura 6 - D).

\subsubsection{Dificuldades nos estudos não presenciais - Turma 1}

Para identificar as dificuldades dos alunos na modalidade de ensino não presencial foram levantados os seguintes questionamentos: possui disciplina nos estudos, organização do tempo dedicado a cada matéria (Figura 7 - A), dificuldade em 
entender os tópicos sem a presença do professor (Figura 7 - B), cansaço em relação ao estudo não presencial (Figura 7 - C), número excessivo de atividades (Figura 7 - D), trabalha e tem pouco tempo para se dedicar (Figura 7 - E), falta do ambiente escolar (Figura 7 - F) e não tem problemas com o ensino não presencial (Figura 7 - G. ). A fim de obter um parâmetro das dificuldades, a pergunta no questionário para a coleta destes dados fora colocada em múltiplas escolhas do qual o estudante poderia assinalar mais de uma opção. Com isso, o resultado obtido foi:

Figura 7 - Dificuldades ENP de 16 alunos da Turma 1.

A

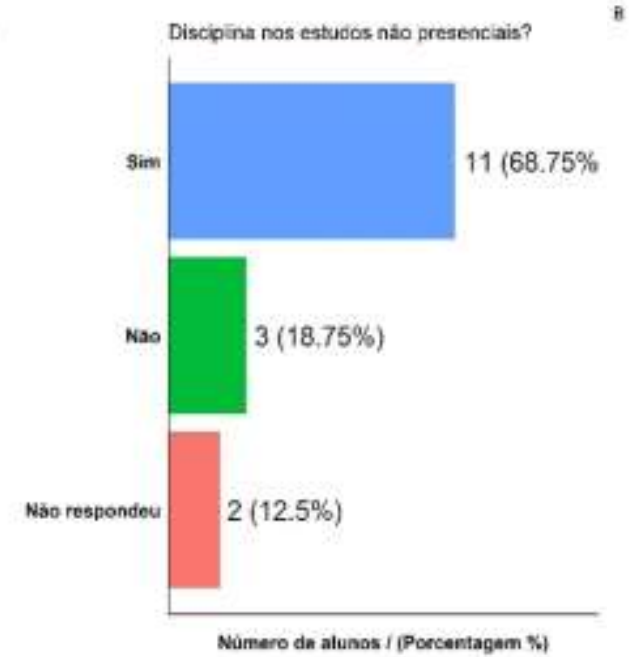

$c$

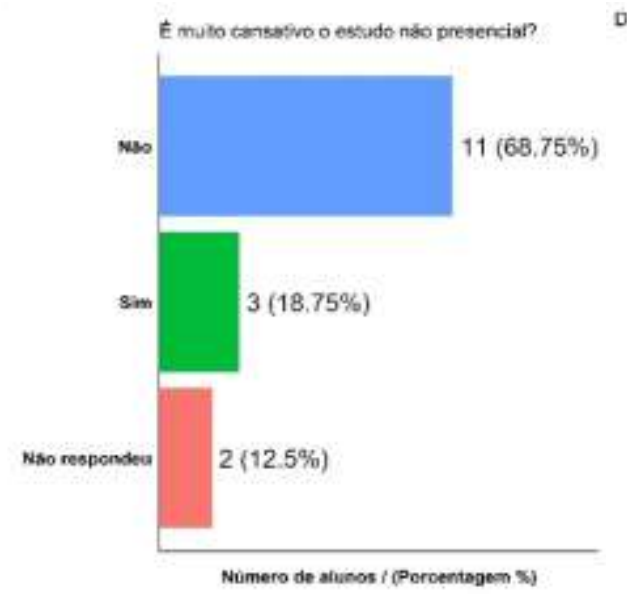

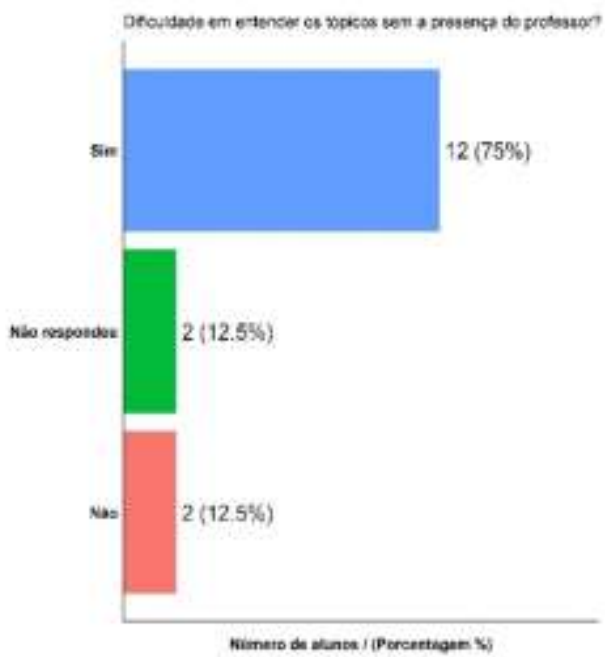
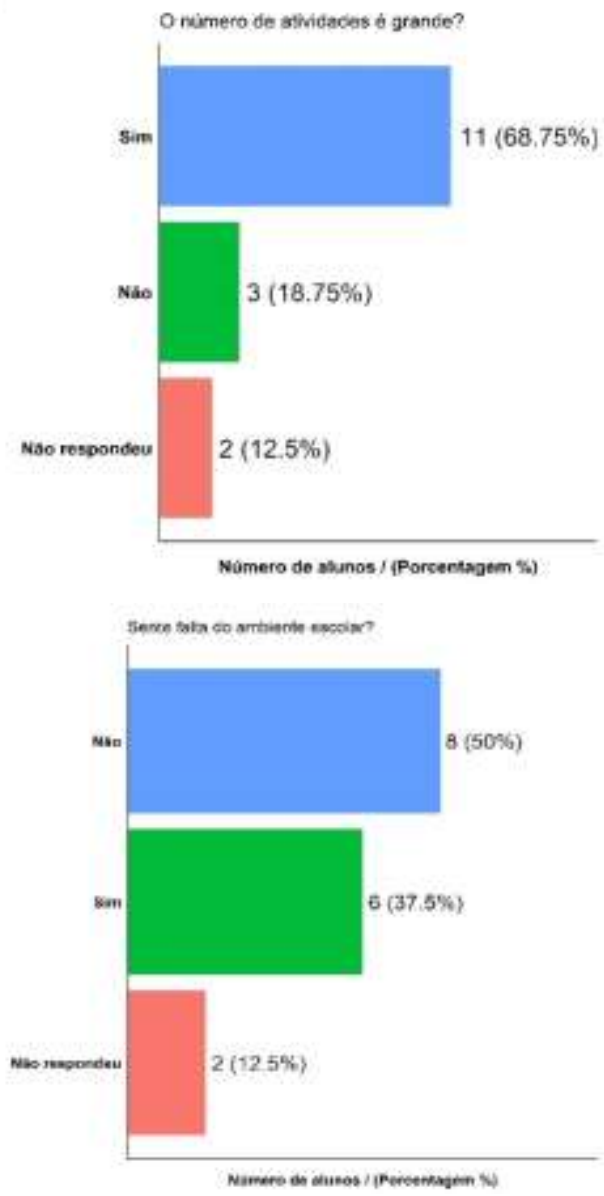


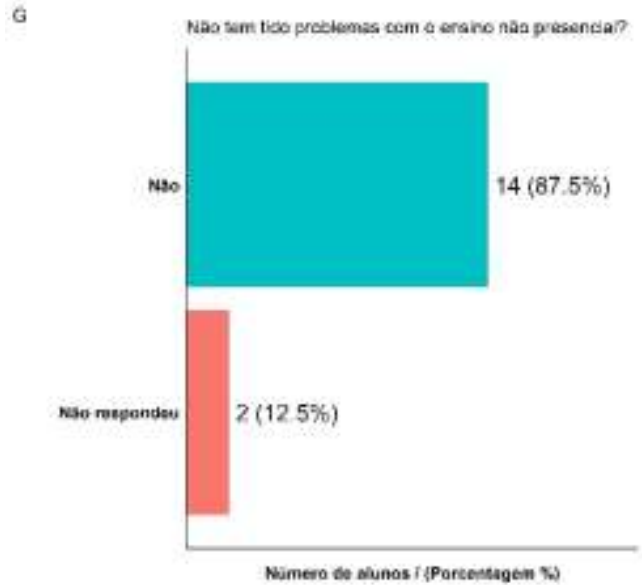

Fonte: Autores (2021).

Dos dezesseis alunos da disciplina de avicultura de corte e postura da Turma 1, onze $(68,75 \%)$ possui dificuldade em estudar e organizar o tempo para a disciplina, três (18,75\%) não tem dificuldade e dois alunos (12,5\%) não responderam (Figura 7-A). Pode-se observar que além da dificuldade de se organizar para os estudos também houve dificuldade em entender o tópico sem a presença do professor. Neste quesito doze alunos (75\%) apresentaram dificuldades, dois alunos $(12,5 \%)$ responderam que não tiveram problemas com ENP e dois alunos (12,5\%) não responderam (Figura 7-B).

Para melhor identificarmos as dificuldades acreditamos que a motivação seria um critério a ser avaliado. Por isso, questionamos se o ENP era cansativo. Observou-se que onze alunos $(68,75 \%)$ responderam que não, três alunos $(18,75 \%)$ responderam sim e dois alunos não responderam (Figura 7 - C). Tais considerações foram ainda validadas a partir da interpretação do questionamento que buscava apurar se o número de atividades era amplo no ENP. Notou-se que onze alunos $(68,75 \%)$ responderam que sim, três alunos $(18,75 \%)$ responderam que não e dois alunos $(12,5 \%)$ não responderam (Figura 7 D).

Ao questionar sobre o tempo e disciplina em relação ao ENP buscamos atentar para o motivo que levaria os alunos a terem maiores dificuldades. Para tanto, foi necessário levantar os dados relativos às atividades simultâneas no período em questão. Conforme as respostas enviadas nove alunos $(56,25 \%)$ realizavam outras atividades, cinco alunos $(31,25 \%)$ não estavam trabalhando e dois alunos (12,5\%) não responderam (Figura 7 -E). As atividades levantadas e exercidas pelos alunos além das acadêmicas foram auxílios aos serviços das famílias, principalmente no meio rural.

Para avaliar os aspectos sociais e culturais ligados à socialização concernente ao ensino presencial questionamos se o aluno sentia falta do ambiente escolar. Diante das respostas observou-se que oito alunos (50\%) responderam que não, seis alunos $(37,5 \%)$ responderam que sim e dois alunos (12,5\%) não responderam (Figura 7 - F).

Na particularidade da observação sobre a dificuldade em relação ao ENP lançamos a última opção na busca por evidenciar a ausência de problemas com a modalidade. Foi constatado que quatorze alunos (87,5\%) marcaram a alternativa que não tinha tido dificuldade com ensino não presencial e dois alunos (12,5\%) não responderam (Figura $7-\mathrm{G})$. Este resultado respalda assim as respostas anteriores.

\subsubsection{Dificuldades nos estudos não presenciais - Turma 2}

Do mesmo modo que a turma 1 recebeu o questionário, a Turma 2 também respondeu sobre dificuldades enfrentadas, na disciplina dos estudos e organização do tempo para a matéria (Figura 8 - A), dificuldades em entender os tópicos sem a presença do professor (Figura 8 - B), cansaço no estudo não presencial (Figura 8 - C), número excessivo de atividades (Figura 8 
- D), falta de tempo (Figura 8 - E), falta do ambiente escolar (Figura 8 - F) e se não enfrentava problemas quanto ao ensino não presencial (Figura 8 - G. ). Ressalta-se que nesta opção, o questionário possibilitava múltiplas escolhas nas respostas, de tal forma que os (as) estudantes poderia marcar mais de uma alternativa.

Figura 8 - Dificuldades ENP de 12 alunos da Turma 2.

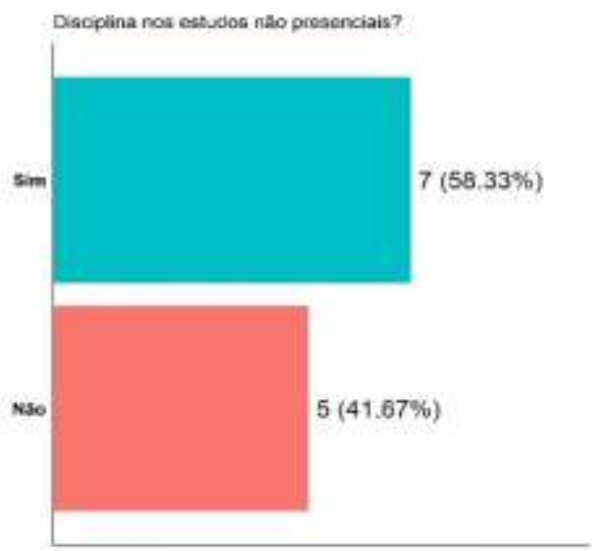

c

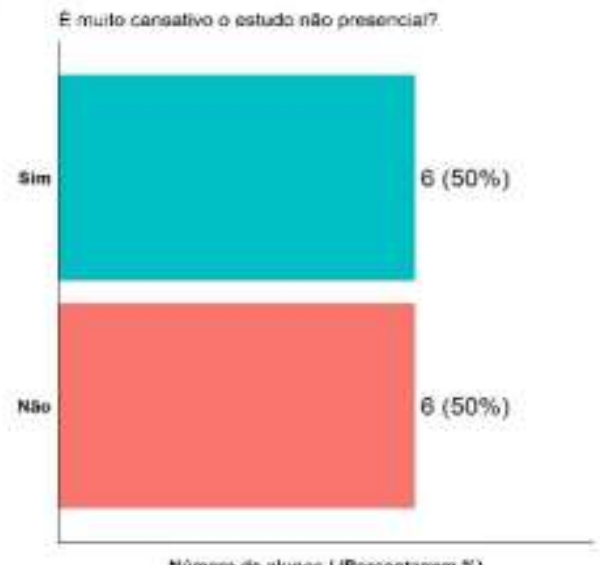

Nümero se alunos f (Porcentagem X)

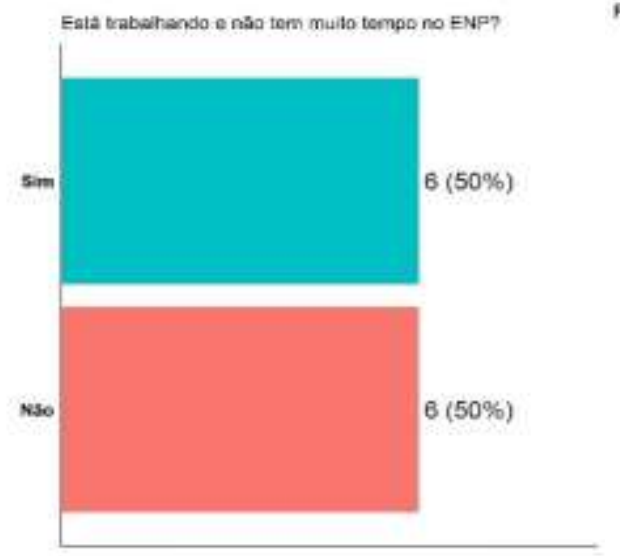

Numero do atunos / (Porcentagem \&.
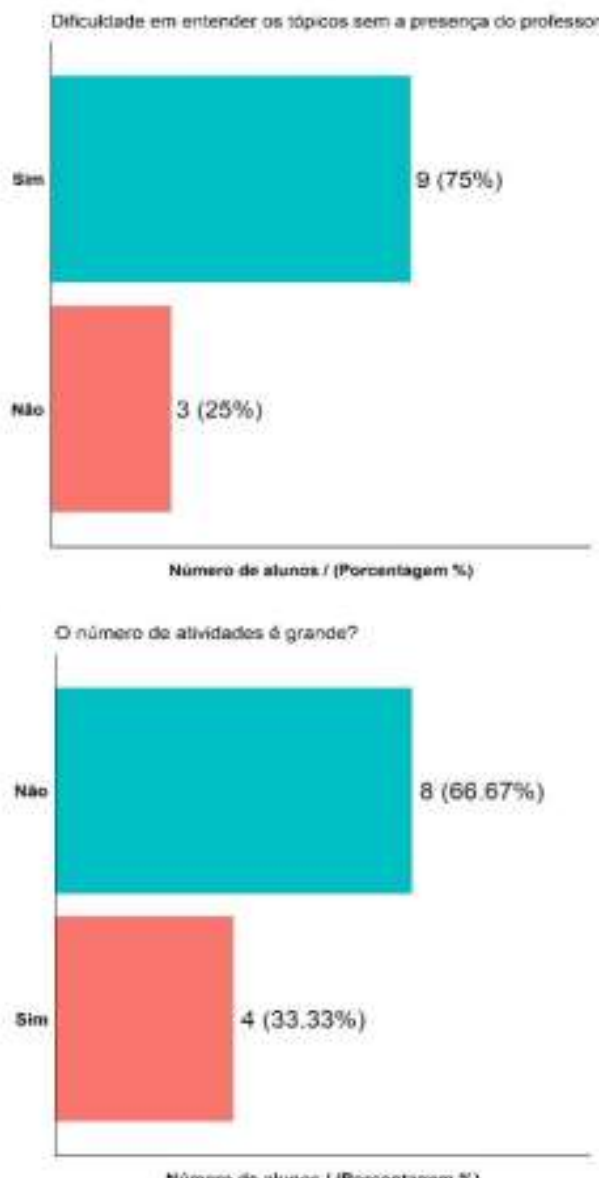

Nümers Ge alunos f (Porcentagem X)

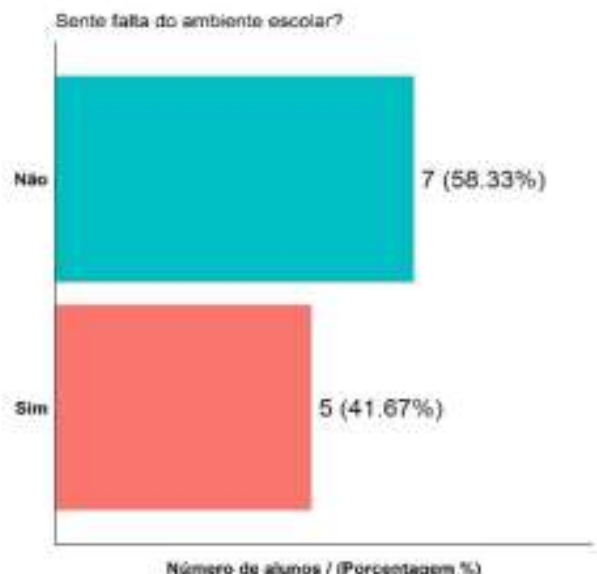




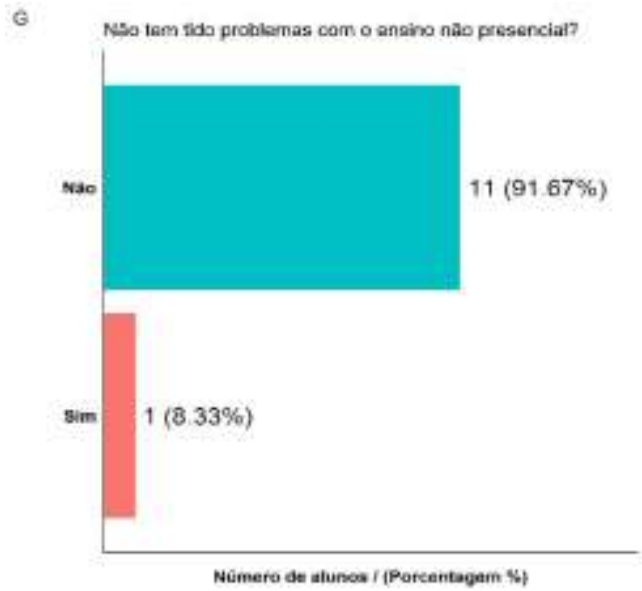

Fonte: Autores (2021).

Dentre os doze alunos da disciplina de avicultura de corte e postura da Turma 2, sete deles (58,33\%) tiveram dificuldade em estudar e organizar o tempo para cada disciplina e cinco (41,67\%) marcaram a opção que não tiveram quaisquer dificuldades (Figura 8 - A). Pode-se observar que além da dificuldade de se organizar para os estudos também houve dificuldade em entender o tópico sem a presença de professor. Neste quesito nove alunos (75\%) apresentaram dificuldades, três alunos (12,5\%) não marcaram esta opção (Figura 8 - B).

No intuito de identificar melhor as dificuldades, acreditamos que a motivação seria um critério a ser avaliado, por isso questionamos se o ENP era cansativo, o que representou um empate, sendo que seis alunos (50\%) afirmaram que sim, e outros seis alunos (50\%) responderam que não (Figura 8 - C). Ao serem questionados se achavam grande o número de atividades no ENP, $(33,33 \%)$ o que representa o quantitativo de 04 estudantes, assinalaram que sim, enquanto $(66,67 \%)$ o que corresponde a 08 estudantes, marcaram a opção não (Figura 8 - D).

Quando perguntados sobre o tempo e disciplina em relação ao ENP acreditamos ser preciso atentar para o motivo que levassem a essas dificuldades, portanto perguntou-se aos alunos sobre suas atividades extracurriculares no período em questão. Conforme as respostas, seis alunos (50\%) realizavam outras atividades e outros seis (50\%) não possuíam outras atividades (Figura 8 - E). As atividades exercidas pelos alunos além das acadêmicas foram empregos em estabelecimentos comerciais e auxílio nos serviços em casa, estes últimos principalmente no meio rural.

$\mathrm{Na}$ análise dos aspectos sociais e culturais da importância da socialização que acontece no ensino presencial, interessounos, questionar se o aluno sentia falta do ambiente escolar. Diante das respostas notou-se que sete alunos $(58,33 \%)$ responderam que não, cinco alunos $(41,67 \%)$ responderam que sim (Figura 8 - F).

Em vista, das particularidades observadas sobre as dificuldades em relação ao ENP, teve a última opção que evidenciava se o aluno não teve problemas com a modalidade. Foi constatado que 11 alunos $(91,67 \%)$ marcaram a alternativa que não estavam tendo dificuldades com ensino não presencial e 1 aluno $(8,33 \%)$ respondeu que estava tendo problema com o ENP (Figura 8 G).

\subsubsection{Estudo das possibilidades de melhorias nos estudos não presenciais - Turma 1}

Para analisar a avaliação dos alunos a respeito das possiblidades de melhorias nos estudos não presenciais foram feitos alguns questionamentos, sendo eles: uso de um computador ou notebook (Figura 9 - A), internet de melhor qualidade (Figura 9 - B), videoaulas (Figura 9 - C), ambiente (lugar mais confortável para estudar) (Figura 9 - D). Em cada questão o aluno poderia marcar mais de uma opção relacionada à melhoria nos estudos não presenciais. 
Research, Society and Development, v. 10, n. 9, e34610917284, 2021

(CC BY 4.0) | ISSN 2525-3409 | DOI: http://dx.doi.org/10.33448/rsd-v10i9.17284

Figura 9 - Estudo das possibilidades de melhorias nos estudos não presenciais - Turma 1.

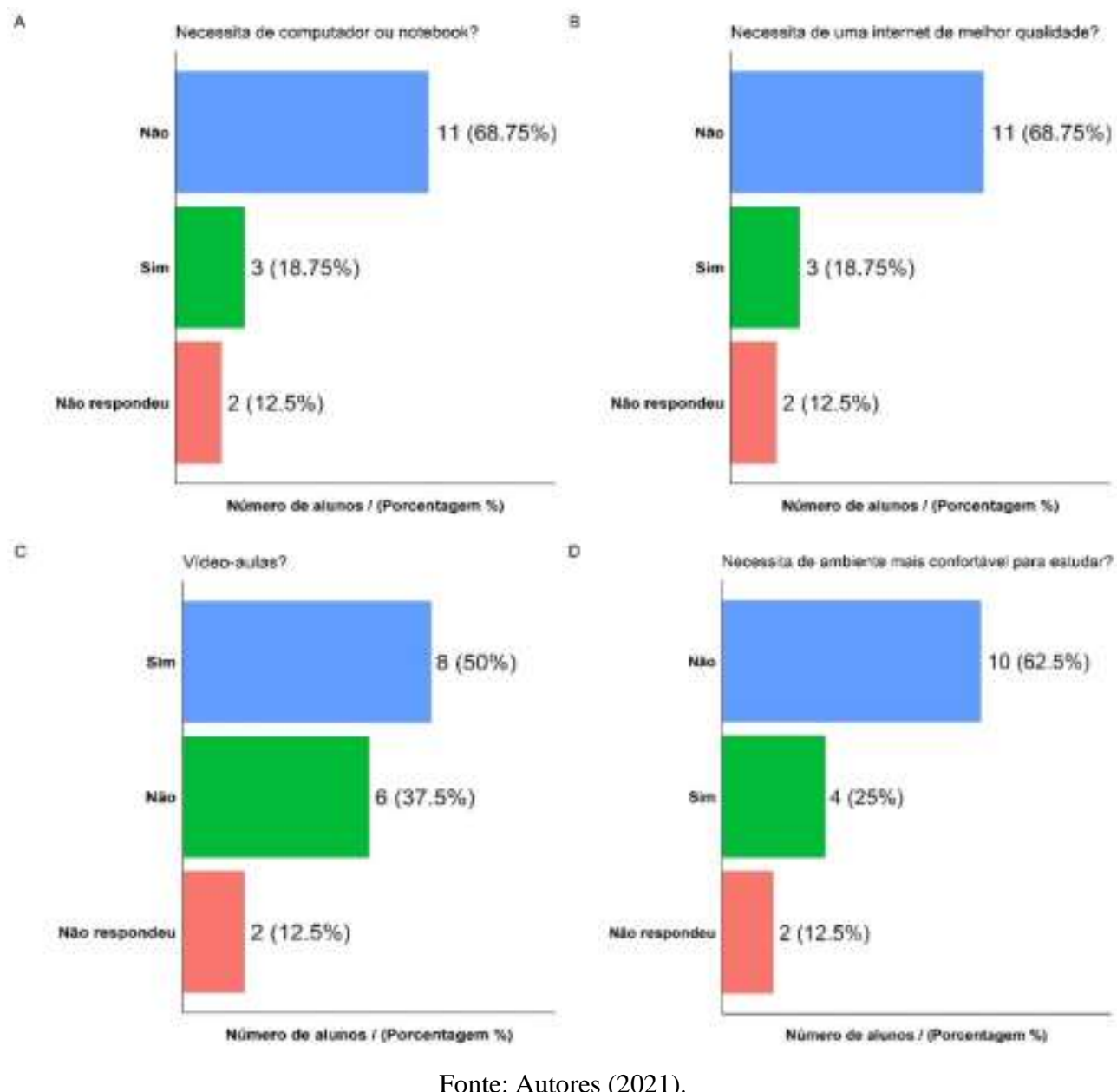

Fonte: Autores (2021).

Ao compilarmos as respostas das opções para melhorias no ENP foi possível observar que, dentre os dezesseis alunos (Figura 9) oito deles (50\%) optaram por videoaulas, seguida da opção de um ambiente mais confortável para estudar, enquanto $(25 \%)$ referente a quatro alunos, optaram pela alternativa da obtenção de um computador ou notebook, $(18,75 \%)$ três estudantes assinalaram a necessidade de uma internet de melhor qualidade.

\subsubsection{Estudo das possibilidades de melhorias nos estudos não presenciais - Turma 2}

Para avaliar o que os alunos optariam para melhorar os estudos não presenciais apresentou-lhes, conforme acima descrito o questionário com as perguntas sobre o uso de um computador ou notebook (Figura 10 - A), uma internet de melhor qualidade (Figura 10 - B), videoaulas (Figura 10 -C), quanto ao ambiente (lugar mais confortável para estudar) (Figura 10 - D). 
Research, Society and Development, v. 10, n. 9, e34610917284, 2021

(CC BY 4.0) | ISSN 2525-3409 | DOI: http://dx.doi.org/10.33448/rsd-v10i9.17284

Figura 10 - Estudo das possibilidades de melhorias nos estudos não presenciais - Turma 2.
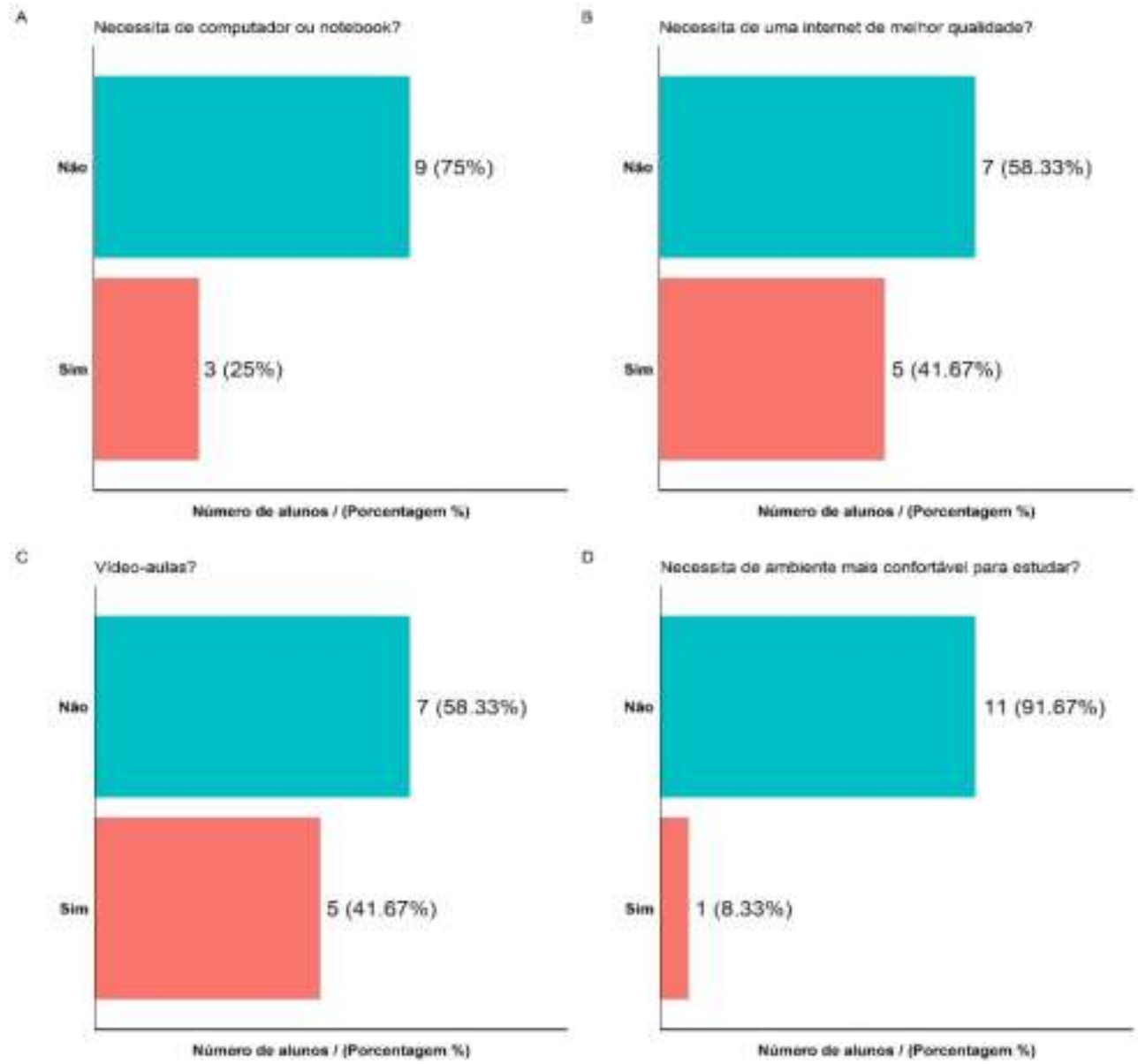

Fonte: Autores (2021).

Nesta compilação, obteve-se a inferência que dentre os doze estudantes (41,67\%) cinco alunos destacaram a necessidade em melhorar as videoaulas, bem como, na mesma proporção, apontaram para a necessidade de obterem uma internet de melhor qualidade, $(25 \%)$ dos estudantes disseram que carecem de computadores ou notebook melhores e por fim, $(8,33 \%)$ assinalaram que as melhorias nos estudos não presenciais estão relacionadas ao um ambiente mais confortável para estudar.

\subsubsection{Avaliação sobre o uso do mapa conceitual - Turma 1}

Para avaliar o uso do mapa conceitual perguntamos para os alunos da Turma 1 a sua opinião a respeito do uso do mapa conceitual para o ENP (Figura 11 - A) e sua satisfação em cursar a disciplina de Avicultura (Figura 11 - B). 
Figura 11 - Uso do mapa conceitual para o ENP (A) e Satisfação em cursar a disciplina de Avicultura (B).

A

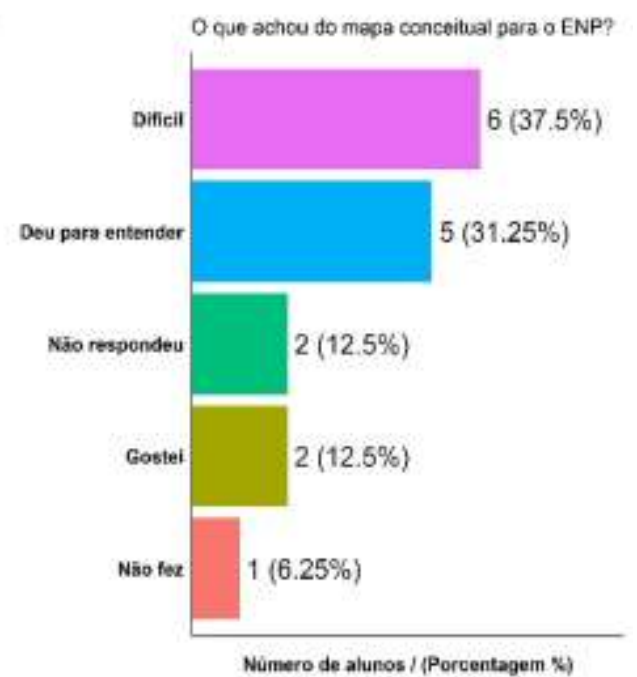

B

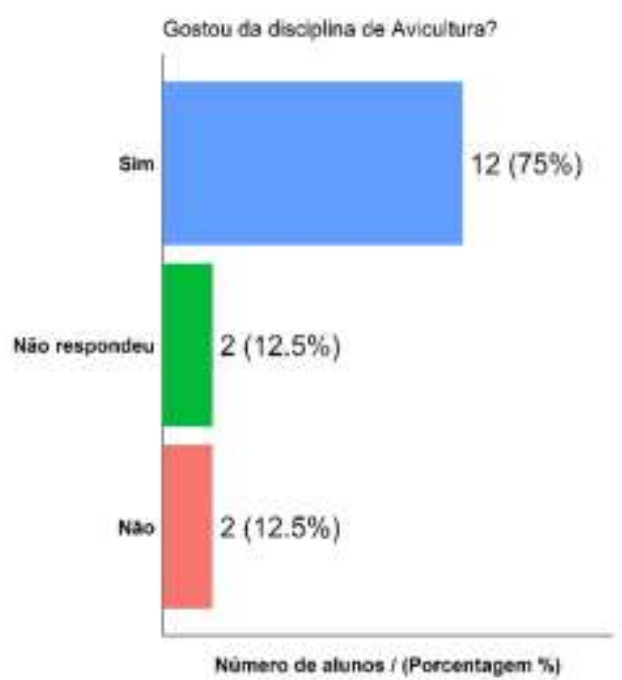

Fonte: Autores (2021).

Verificou-se que seis alunos (37,5\%) acharam difícil a elaboração do mapa (12,5\%) conceitual, cinco alunos (31,25\%) responderam que entenderam o conceito, dois alunos gostaram da estratégia do uso do mapa conceitual, dois alunos (12,5\%) não responderam e um aluno não fez o mapa conceitual (Figura 11 - A).

No que diz respeito à percepção dos estudantes em relação à disciplina de avicultura e sua identificação com a área cerca de doze alunos $(75 \%)$ responderam que gostaram da matéria, dois alunos $(12,5 \%)$ não gostaram da área e dois alunos $(12,5 \%)$ não responderam (Figura 11 - B). Cabe enfatizar que essa turma teve parte da disciplina de Avicultura realizada de forma presencial sondamos a satisfação desses alunos em relação ao contexto do ensino não presencial o que pode ser observado de modo satisfatório. Como a pergunta no questionário possibilitava para além da marcação das duas opções a justificativa da resposta, os estudantes que assinalaram que gostaram da disciplina expuseram que o conteúdo era de relevância porque a avicultura favorecia a possibilidade de emprego, como também a vivência com a criação de aves etc. Já os alunos que responderam que não gostaram do conteúdo, justificou-se que preferem a área da agricultura, porém como a disciplina de avicultura faz parte da matriz curricular, apenas cursaram sem uma identificação singularizada.

\subsubsection{Avaliação sobre o uso do Mapa Conceitual - Turma 2}

Para avaliar a utilização do mapa conceitual perguntamos a opinião dos alunos da turma 2 quanto a sua satisfação (Figura 12 - A) e o mesmo questionamento feito para a disciplina de Avicultura (Figura 12 - B). 
Figura 12 - Uso do mapa conceitual para o ENP (A) e Satisfação em cursar a disciplina de Avicultura (B).

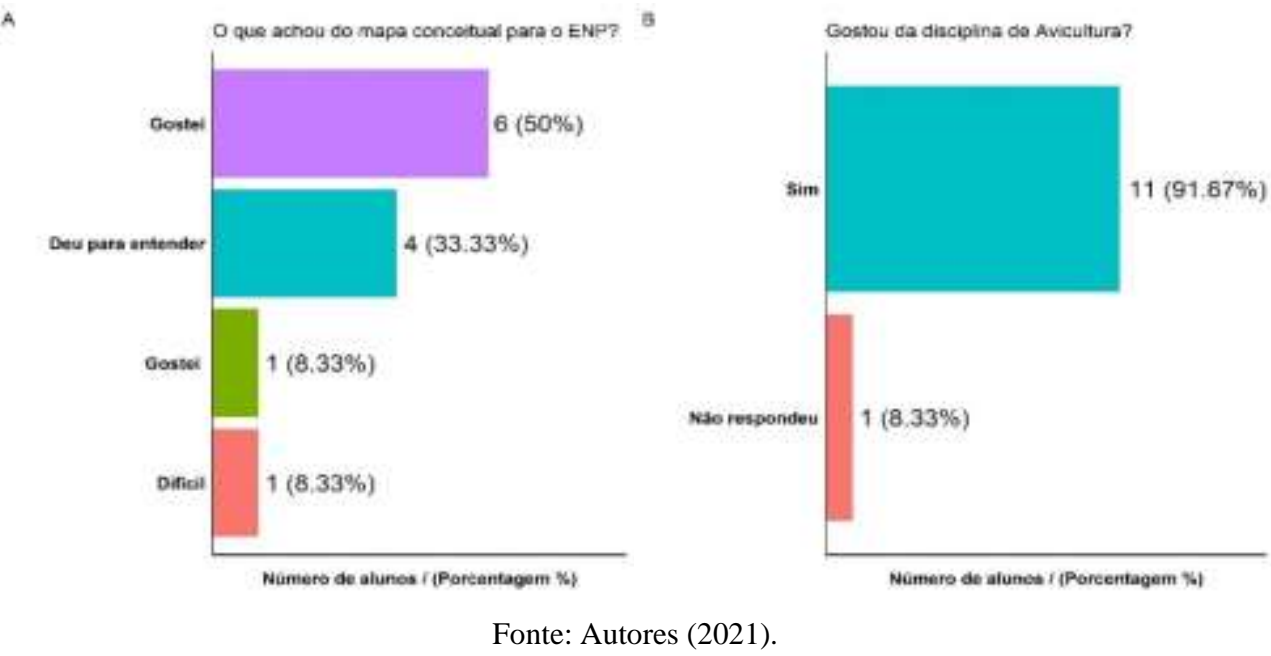

Verificou-se que seis alunos (50\%) gostaram de elaborar o mapa conceitual, quatro alunos $(31,25 \%)$ responderam que deu para entender, um aluno gostou e um aluno respondeu que achou difícil construir o mapa conceitual (Figura 12 - A). Para os alunos que gostaram da estratégia do uso do mapa conceitual foi interessante a justificativa, pois para eles o mapa conceitual consistia em uma síntese do conteúdo. Destacou-se também que os alunos com maiores dificuldades se apresentavam ausentes nos encontros e entregaram as atividades incompletas.

$\mathrm{Na}$ intenção de obter uma visão geral a respeito da disciplina de avicultura questionamos a identificação com a área. Cerca de onze alunos $(91,67 \%)$ responderam que gostaram da disciplina, um aluno $(8,33 \%)$ não gostou da área (Figura 12 - B). As justificativas para os alunos que gostaram da disciplina e afirmaram ser um conteúdo interessante foram: avicultura como oportunidade de trabalho, além de familiarizarem e desenvolverem seus aprendizados na vivência com as criações dos quais possuem acesso. Um aluno respondeu que não gostou da disciplina e que achou o assunto desinteressante.

\subsection{Discussão}

Os dados revelam que os mapas conceituais enquanto estratégia de ensino, aprendizagem e avaliação teve um resultado particularizado, no que diz respeito à estrutura cognitiva a aprendizagem significativa formulada por David Ausubel e a teoria da educação do Joseph Novak. Deste modo, a teoria de mapas conceituais baseada na teoria de aprendizagem significativa, promoveu a compreensão dos temas ao passo que a representação gráfica de conhecimentos indicou relações entre os conceitos. E os conceitos foram representados de forma hierárquica, do nível mais simples para o mais complexo.

Isto se deu por meio das videoaulas na premissa de contextualização do novo conteúdo com o conhecimento prévio, promovendo uma ancoragem de novos conceitos, através da integração dos ensinamentos da biologia, química, física, geografia, dentre outras áreas na compreensão do tema, avicultura. Nesta perspectiva trabalhou-se as experiências, vivências e novos conhecimentos adquiridos dos estudantes na intenção de motivá-los a aprender, principalmente na modalidade de ensino não presencial.

Ao considerarmos o mapa conceitual enquanto estratégia de ensino, aprendizagem e avaliação, percebemos que os conteúdos se tornam favoráveis para as discussões conteudista e proporcionam bons rendimentos educacionais, já que por este meio é possível conduzir os (as) estudantes ao um aprendizado significativo.

E partindo dos dados obtidos, os alunos que gostaram da estratégia do uso do mapa conceitual explicaram que para eles o mapa conceitual funcionou como uma síntese do conteúdo. Pode-se perceber também que mesmo aqueles estudantes que 
relataram dificuldades na elaboração do mapa conceitual obtiveram um bom aprendizado, pois demonstraram, a partir da apresentação dos conceitos uma relação entre eles, indicando assim, a aquisição do conhecimento por meio do conteúdo ministrado.

Diante disso, destaca-se que no contexto da realização das atividades do ENP apenas o uso de celular pode ser desmotivador e cansativo, fato este que pode ser somado ao grande número de atividades, já que os alunos tinham quatorze disciplinas no primeiro ano.

Verificamos que independentemente da localização da moradia dos alunos, as dificuldades encontradas tanto em relação ao acesso e qualidade da internet quanto aos desafios impostos pela modalidade de ENP, são fatos que não nos cabe mensurar, pois para aqueles alunos que demonstraram disciplina, frequência nos encontros síncronos, presença na monitoria e autonomia nos estudos, tiveram superação das dificuldades e obtiveram rendimento superior aos demais. Enquanto para outros, fora extremamente cansativo e fadigoso pela sobrecarga em relação ao quantitativo de atividades na rotina da modalidade ENP propiciada no estudo remoto e suas outras obrigações extracurriculares.

Evidentemente, nota-se que além da estratégia (mapas conceituais) e da modalidade de ensino (Presencial ou ENP) o aprendizado é individual e existem outros fatores que influenciam na aquisição do conhecimento dentre eles: vivências, experiências, condições socioeconômicos e culturais para além da motivação e estímulo que a disciplina pode oferecer. Diante disso, a análise destes fatores através de um questionário não consegue sintetizar todos os fatores que interferem ou auxiliariam no aprendizado, mas salienta algumas condições e contextos dos quais os estudantes estão inseridos.

É interessante frisar que a pesquisa foi feita em duas turmas em momentos diferentes e os resultados foram semelhantes. Uma teve parte presencial e logo em seguida ENP (Turma 1) e a outra ateve-se somente no ENP (Turma 2). Desta forma, a apresentação dos dados fora colocada de forma mais homogênea possível a fim de situar que mesmo na atual condição pandêmica provocada pela COVID -19 fica difícil determinar o impacto do ensino não presencial em relação ao ensino presencial. São inúmeros os fatores envolvidos e que variam individualmente.

O contexto da estratégia de ensino com os desafios dos alunos à modalidade de ENP, nesta pesquisa, estão interligados, isto porque as dificuldades encontradas tanto em relação ao acesso e qualidade da internet, como também os conflitos impostos pelo ensino remoto, sopesam em toda uma estrutura de estudos.

\section{Considerações Finais}

Pensando nos processos que a tríade ensino-aprendizagem-avaliação dimensiona, pode-se inferir neste artigo, que incluir métodos mediadores podem facilitar e evidenciar as estratégias educacionais. A reflexão e práticas das possibilidades pedagógicas corroboram com as competências e habilidades do desenvolvimento dos (das) estudantes. Diante dessa perspectiva, o ensino se caracteriza pelo ato e efeito do partilhar conhecimentos. A aprendizagem por sua vez, é a incorporação destes conhecimentos de forma cognitiva que pode ser agregada ou modificada pelo formato que o ensino é perpassado de modo que a avalição se torna o resultado destas assimilações.

A inclusão de metodologias para ensino, aprendizagem e avaliação que busca diversificar as estratégias e as ferramentas na tentativa de expor o conteúdo e obter bom resultado para todos os alunos, o uso de mapa conceitual pode auxiliar na construção do conhecimento. Contudo deve-se compreender que o aluno para entender e interagir com o sistema do mundo físico se faz necessária a contextualização do novo conhecimento dentro da sua realidade, levando-se em conta as fontes provenientes dos conceitos (biológicas, linguísticas, sociais e pessoais).

O diálogo necessário para um melhor aprofundamento das práticas pedagógicas e abordado neste artigo foi enriquecido pelo uso de mapas conceituais nas estratégias de ensino, aprendizagem e avaliação. Dessa forma, os instrumentos e métodos 
desenvolvidos solicitaram um empenho reflexivo das práticas pedagógicas de forma propositiva a fim de elucidar o conhecimento com subsídios pedagógicos ajustados a realidade circunscrita.

Portanto, os objetivos preponderados para a eficácia na ação pedagógica permearam distintos processos contemplativos que resultaram na didática da prática. Com isso, o educar não se ateve apenas em ater-se puramente aos conhecimentos científicos ou os aportes tecnológicos hábeis, mas aperfeiçoou as propriedades do ensino, de modo motivador, dando condições para que os (as) estudantes tivessem direcionamentos dentro da ótica prevista nos conteúdos programáticos.

Para tanto, as atividades viabilizadas tiveram a intenção de provocar nos indivíduos as construções de seus conhecimentos que, por sua vez, possuem caráter contínuo e como tal passam por processos que acarretam o aprendizado.

Conforme Souza et al (2017), o processo de aprendizagem por meio de mapas conceituais torna o ensino personalizado e único para cada educando. Além disso, permite conexões com o tema de estudo e atribui a este um significado, de acordo com o que o educando já sabia e o novo.

Com isso, os (as) estudantes envolve-se com o seu conhecimento efetivando na aprendizagem significativa. Nesse sentido, adota-se os mapas conceituais como recurso facilitador do qual o professor pode visualizar o desenvolvimento de todo processo de ensino, aprendizagem e avaliação e ainda, garantir subsídios que revelam quais mudanças e intervenções devem ser tomadas para alcançar os objetivos e competências da aprendizagem. Por outro lado, o uso dos mapas no ensino também é capaz de externalizar o processo de aprendizagem fazendo com que o (a) estudante organize sua estrutura cognitiva aceitando que como percussor de do saber, este, pode relacionar seus conhecimentos e aprendizagem.

Por fim, cabe ainda ressaltar que a aprendizagem significativa formulada por David Ausubel e a teoria da educação de Joseph Novak muito auxiliam nos percursos do ensino, aprendizagem e avaliação, pois promovem a análise dos estudantes bem como solicita do professor (educador) a autoanálise, o que instiga a reflexão contínua. E desta maneira, o conhecimento pode abarcar caminhos distintos, não apenas na contextualização dos mapas conceituais, mas por todas as estratégias que seja requerida a assimilação de conceitos e considerações cuja o assunto deva ser priorizado. Portanto, apresentou-se neste artigo um dos caminhos a ser fomentado estas teorias, e por esta razão deixa-se firmado o desejo de futuramente realizar outras investigações dentro deste campo.

\section{Referências}

Audy, J. H. K. Mapas Conceituais e a aprendizagem significativa. Disponível em: https://jorgeaudy.com/2014/06/08/mapas-conceituais/. Acesso em abr. 2021. Campelo, L. F. Promovendo a Aprendizagem Colaborativa com Mapas Conceituais nas Aulas de Geografia. Revista Olh@ res. Guarulhos, V. 5, N², 2017.

Correia, P. R. M.; NardI, A. O que revelam os mapas conceituais dos meus alunos? Avaliando o conhecimento declarativo sobre a evolução do universo. Revista Ciência e Educação. Vol.25 No.3 Bauru July/Sept. 2019.

Hattie, J. A. C. Visible Learning. A synthesis of over 800 meta-analyses relating to achievement. London: Routledge, 378P, 2009.

Joseph, D. Novak; Cañas, A. J. Práxis Educativa. Ponta Grossa, V.5, n. 1, p. 9-29, jan - junho 2010. Disponível em: http://www.periódicosuepg.br. Acesso em abr.2021.

Kubo, O. M.; Botomé, S. P. Ensino-Aprendizagem: Uma Interação Entre Dois Processos Comportamentais. Disponível em: https://revistas.ufpr.br/psicologia/article/vi ew/3321. Acessado em Mar. 2021.

Mintzes, J. J.; Wandersee, J. H.; Novak, J. D. Assessing science understanding: a human constructivist view. San Diego: Academic Press, 2000.

Novak, J. D.; Canãs, A. J. A teoria subjacente aos mapas conceituais e como elaborá-los e usá-los. Práxis Educativa, Ponta Grossa, v.5, n.1, p. 9-29, jan.-jun. 2010. Disponível em: http://www.periodicos.uepg.br. Acesso em mar.2021

R Core Team. R: A Language and Environment for Statistical Computing. Vienna, Austria: R Foundation for Statistical Computing. 2018. Disponível em: http://www.R-project.org/. Acesso em mar.2021.

Silva, E. C. da. Mapas Conceituais: Propostas De Aprendizagem E Avaliação. Administração: Ensino E Pesquisa. 2015. Disponível em:https://doi.org/10.13058/raep. 2015.v16n4.385. Acesso em abr. 2021. 
Research, Society and Development, v. 10, n. 9, e34610917284, 2021

(CC BY 4.0) | ISSN 2525-3409 | DOI: http://dx.doi.org/10.33448/rsd-v10i9.17284

Silva, H.; Lopes, J.; Dominguez, C. A aprendizagem cooperativa e os mapas de conceitos na promoção do pensamento crítico e criativo: uma experiência no ensino superior. Revista Lusófona de Educação. V. 45, No 45, 2019. https://revistas.ulusofona.pt/index.php/rleducacao/article/view/6998. Acesso em mar. 2021.

Silva, W; Ribas, C. G; Mendes, A. P. Aprendizagem significativa e mapas conceituais. IV Seminário Internacional de Representações Sociais, Subjetividade e Educação - SIRSSE - PUC - Paraná - Campus Curitiba 28 a 31 de março de 2017.

Souza, G. F., Pinheiro, N. A. M., Miquelin, A. F. Mapas Conceituais no Ensino de Ciências: Uma proposta para aprendizagem significativa de conceitos significativos nos anos iniciais. Cadernos de estratégias pedagógicas para os professores dos anos iniciais de ensino fundamental. Universidade Tecnológica Federal do Paraná. Ponta Grossa, 2017. 30p.

Souza, M.; Banhos, M. Mapas conceituais. Apostila, 2016.: file://C:/Users/naelana/Downloads/MAPAS\%20CONCEITUAIS.\%20Marivald o\%20Souza\%20Marlene\%20Banhos.pdf.

Tolfo, C. Concept Maps and promoting active classroom participation. Research, Society and Development, [S. 1.], v. 9, n. 1, p. e69911630, 2020. DOI: 10.33448/rsd-v9i1.1630. https://rsdjournal.org/index.php/rsd/article/view/1630.

Xavier. G. C. Teorias de Aprendizagem. Apostila (Pós-Graduação em Docência). Instituto Federal Minas Gerais. Arcos, 2019. 54p. 